\title{
Conception and Origination of folk tune in Long March Cantata(长征组歌)
}

\author{
${ }^{1}$ Siyu Tian, ${ }^{2}$ Huibing Tan* \\ ${ }^{1}$ Department of social science and art, College of Humanities and Management, Jinzhou Medical \\ University, Jinzhou, Liaoning, 121001, China \\ ${ }^{2}$ Department of Anatomy, School of Basic Medical Sciences, Jinzhou Medical University, 121001, \\ China
}

ABSTRACT Thoughtful introduction of Chinese choral repertoire, the Long March cantata is contemporarily highly recognized music heritage of large-scale choral work of 10 movements last century in China. The cantata is composed to commemorate 30th anniversary of Long March. The journey of the Long March covered 11 provinces over 4,000 miles and crossed 24 rivers and 18 mountain ranges for over 370 days. The libretto is a set of narrative poetry by General Hua Xiao in Sept, 1964. "Long March Cantata" is conceptually composed based on "Where to go and where to say, when you hear the melody, the audiences will realize that it's Guizhou, Yunnan, North Shaanxi ... Wherever the music is performed, it should restore the imaging of local feeling". This article mainly discusses its absorption of Chinese folk music based on Chinese pentatonic scales in music composition. Among them, movement one "Farewell (Leave the Base Area)" uses Jiangxi folk tunes, and the movement three "The Zunyi Conference, the Brilliance" use Guizhou tunes according to composers. For examples, in the movement four " Raid of Four times Cross Red Water ", Yunnan tunes are used, and in the movement seven "Arrive Wuqi Town", the northern Shaanxi tunes are used. In movement eight "Cheers" and movement nine "Annunciation", the tune of Changsha in Hunan and Northeast Jiangxi were selected to salute the southeast soldiers respectively. With the instrumental accompaniment of the full western orchestra, bel canto and national folk style signing (non-classical voicing) are well balanced. In order to match folk tune and regional congruency, Chinese traditional musical instruments, erhu (二胡), pipa (三弦), zhudi (bamboo flute, 笛子), suona (Chinese trumpet 唢呐), kuaiban (bamboo castanets, 快板) as well as other Chinese percussion etc. were used with the western symphony orchestra according to historical context.

Keyword: Long March Cantata, folk song, melody, music conception, Chinese choral repertoire

*Correspondence: Huibing Tan. No.40, Section 3, Songpo Road, Linghe District Jinzhou City, Liaoning Province, 12100, P.R. China. E-mail: davidtanhb@foxmail.com

\section{CONFLICT OF INTERESTS}

The authors have no conflicts of interest to declare. 


\title{
长征组歌民歌元素分析
}

\author{
${ }^{1}$ 田思宇, 2 谭会兵* \\ ${ }^{1}$ 文学与艺术教研室，人文与管理学院， ${ }^{2}$ 人体解剖学教研室，基础医学院，锦州医科大学
}

摘要: 长征组歌是中国大型合唱作品康塔塔中最成功的典范, 作品有 10 个乐章, 以纪念红 军长征 30 周年而创作。长征行程 2500 千里, 途径 11 个省,穿过 24 条河流, 翻越 18 座山峰。 作品脚本来自萧华将军的叙事诗 $(1964,9)$ 。《长征组歌》立意于“走到哪儿说哪儿的话, 一听 就知道这是到贵州了、到云南了、到陕北了......音乐也得走到哪儿就要还原当地的感觉” 进 行创作构思。包括五声音阶分析, 本文主要探讨了其在音乐创作中对于中国民族民间音乐的 汲取。其中《告别》选用江西音调, 三曲《遵义会议放光辉》选用贵州音调, 四曲《四渡赤 水出奇兵》选用云南音调, 七曲《到吴起镇》选用陕北音调, 六曲《过雪山草地》中运用青 海藏族的音调表现川藏地区的情景等, 八曲《祝捷》九曲《报喜》中分别选用了湖南长沙音 调与江西赣东北表现南方战士的形象。声乐演唱采用美声唱法和民族唱法相互结合, 乐队织 体为管弦乐, 配器上, 运用了中国民族乐器笛子、三弦、琵琶、二胡, 唢呐和快板等。在汲 取民歌素材创造声乐作品, 其歌曲旋律和乐队的中西乐器融合方面取得了成功。

关键词：长征组歌、民歌、旋律、音乐立意、中国合唱曲目 *通讯作者: 谭会兵, 锦州医科大学, 辽宁省锦州市凌河区松坡路三段 40 号, 邮编:121001。 E-mail: davidtanhb@foxmail.com

前言

《长征组歌》是中国上世纪 60 年代创作的声乐作品康塔塔。《长征组歌》的作词者是开国上 将萧华, 由战友文工团晨耕、生茂、唐辑和遇秋作曲 ${ }^{1}$ 。音乐织体是西洋声乐, 作品采用了 众多的民歌素材, 本文作者于 2016 年参加过《长征组歌》排练和演出, 在研习文献基础上, 对作品进行讨论和分析, 借此和读者进行交流和学习, 如果有不当之处, 欢迎批评指导。

\section{1 《告别》}

《告别》主题旋律是五声音阶徵调式, 创作中以大二度小三度的进行为主要运动动机, 有两 个上行纯四度跳进。整体体现出了我国五声性风格。同时也运用了两首民歌的的旋律主题《打 骑兵歌》和《红军胜利歌》

1石祥, 萧华与《长征组歌》, 解放军报 (长征副刊), 2016, 9, 24, p11 
第一次出现“红旗飘, 军号响”的旋律如下, Theme Example 1:

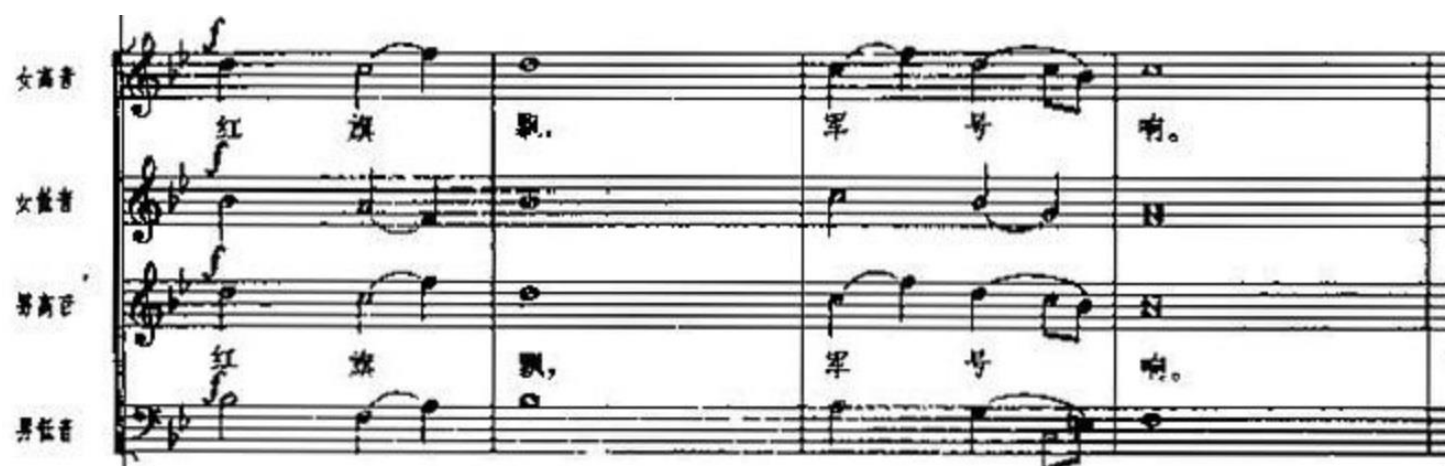

上征途主题 Theme Example 2:

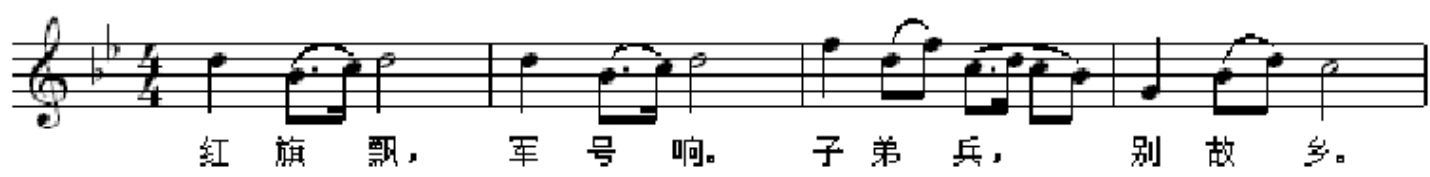

音乐素材《打骑兵歌》主题 ${ }^{2}$, Folk music melody 1:

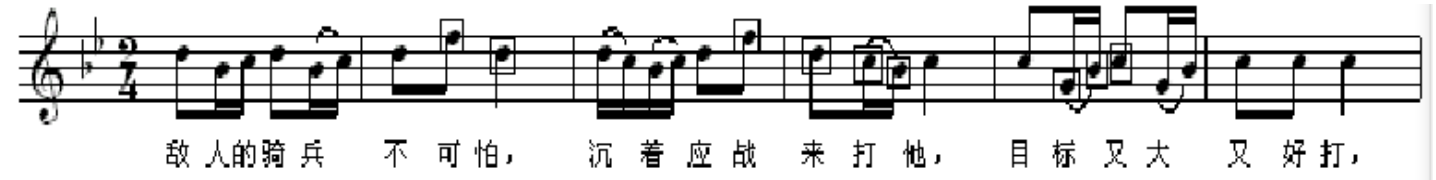

《打骑兵歌》是长征时期由陆定一和李伯到编写的在红军中广为流传的歌曲, 曲调 (曲调最 早来源于沈心工根据民间流行的《马队喇叭调》填词的《竹马》。）曾在红军早期被填词为《粉 碎敌人乌龟壳》, 在长征时期被填词为《渡金沙江胜利歌》 3 。上征途主题旋律是在其基础上, 扩展音域, 缩减节奏型得来的, 由于节奏稳步进行更能祄托出出征沉重的心情, 另外旋律上 去掉相应的装饰音，亦可传达沉重的心情。

上征途主题, Theme Example 3

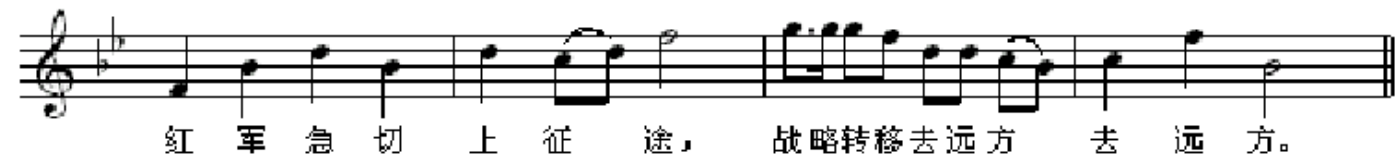

2乐谱引自解放军歌曲选集编辑部.中国工农红军歌曲选[M].内部业务参考资料, 1954.19.

3 参见李双江主编.中国人民解放军音乐史[M].北京: 解放军文艺出版社, 2004 . 
音乐素材《红军胜利歌》主题, Folk music melody 2:

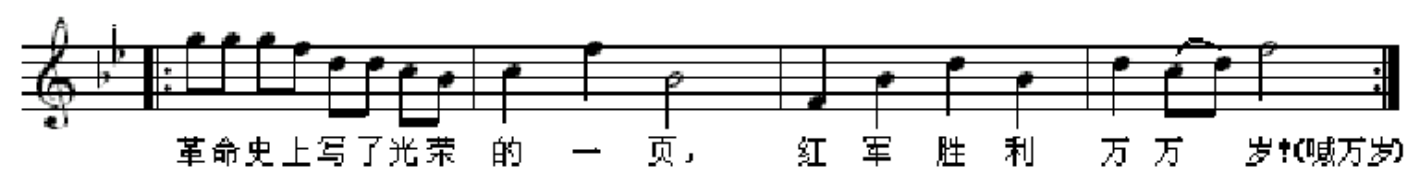

两段皆是以宫商音角音和徵音为骨干音, 并配以辅助音环绕式进行。

另外, 《告别》采用了江西赣南的采茶戏音调, “别亲人”这一主题具有浓郁的赣南采茶戏风 味。笔者在对“别亲人”主题写作分析中, 发现大量赣南采茶戏的乐段中的终止乐汇与其主题 接近。

别亲人主题, Theme Example 4
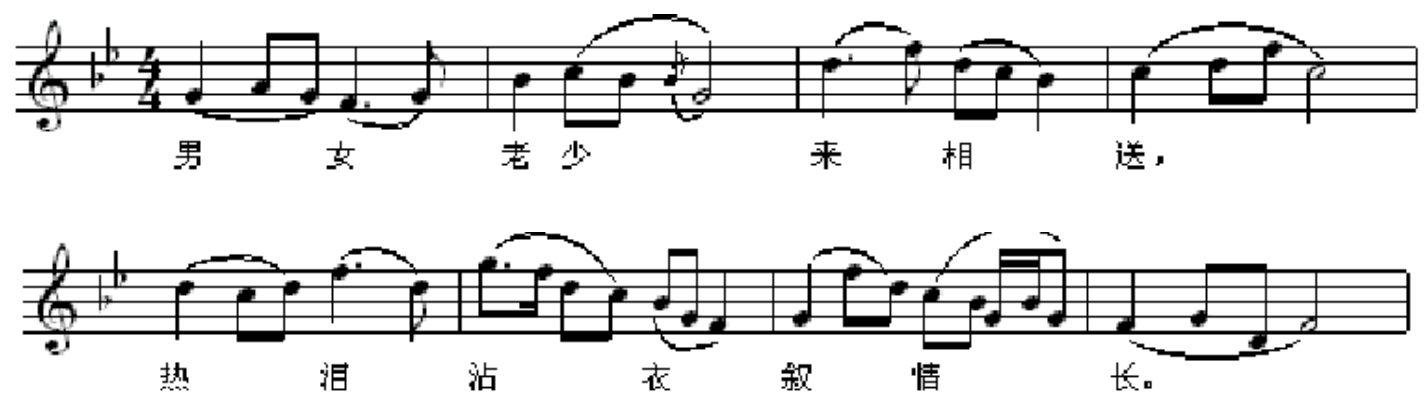

民歌素材《对花调》主题 ${ }^{4}$, Folk music (melody) 3:

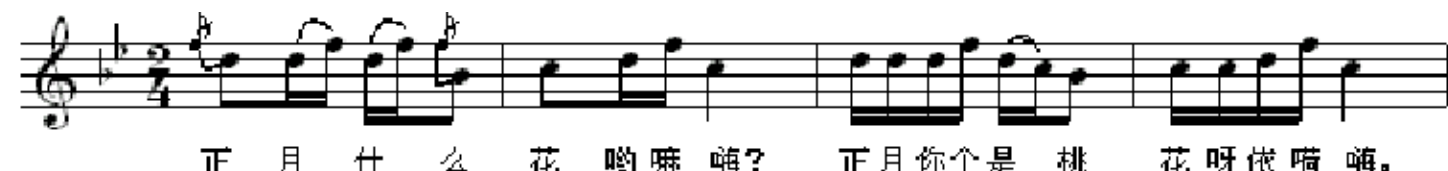

民歌素材《问姓名调》主题 5 , Folk music melody 4:

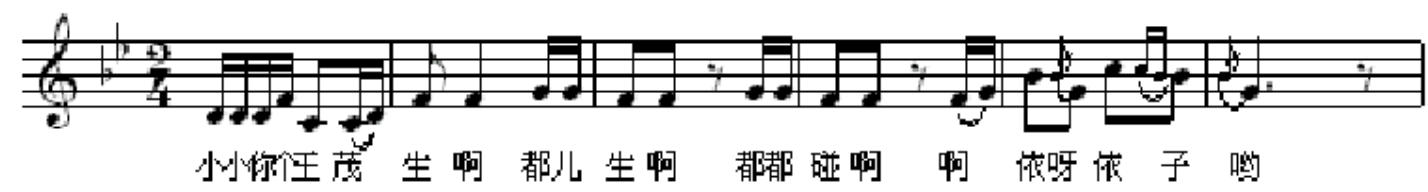

《告别》全曲曲式为起承转合四部曲式, 属于非规范曲式, 调式布局为 $\mathrm{b} \mathrm{B}$ 宫一 $\mathrm{F}$ 徵一 $\mathrm{g}$ 羽

4乐谱引自《中国戏曲音乐集成》全国编辑委员会, 《中国戏曲音乐集成・江西卷》编辑委员会编.中国戏曲 音乐集成・江西卷[M].北京: 中国 ISBN 中心，1999.1860-1861

5 乐谱引自《中国戏曲音乐集成》全国编辑委员会, 《中国戏曲音乐集成・江西卷》编辑委员会编.中国戏曲 音乐集成・江西卷[M].北京：中国 ISBN 中心，1999.1827-1828. 
$-\mathrm{b} B$ 宫一F 徵一b B 宫, 全曲体裁分布为叙事性序曲。

\section{2 《突破封锁线》}

急行军主题, Theme Example 5
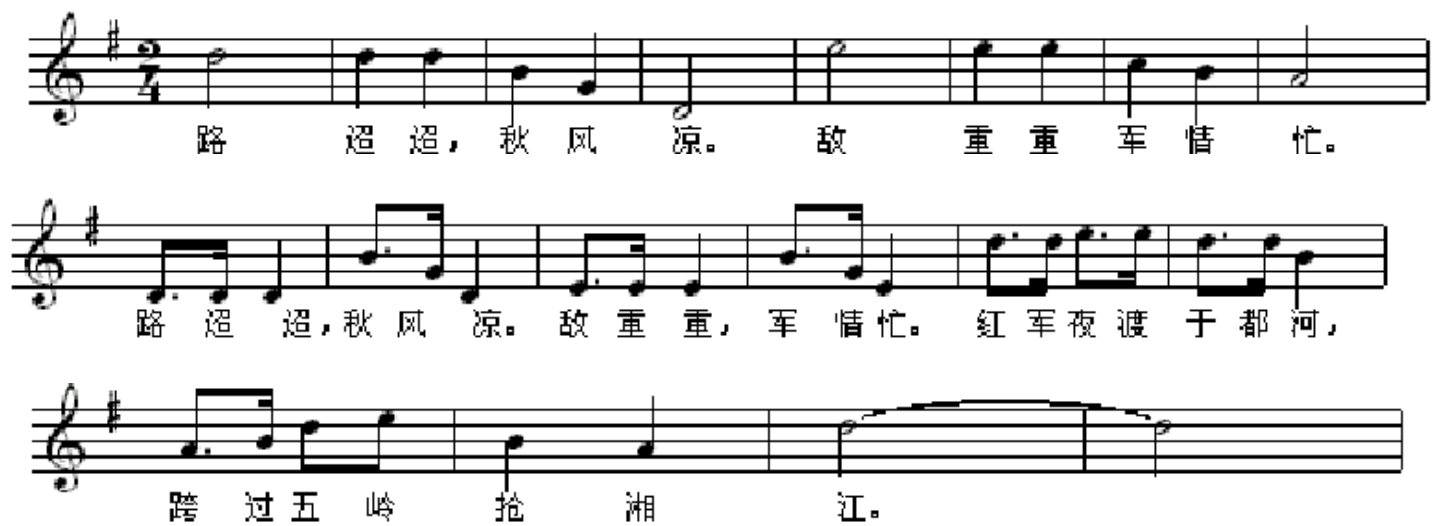

突破封锁线主题, Theme Example 6:

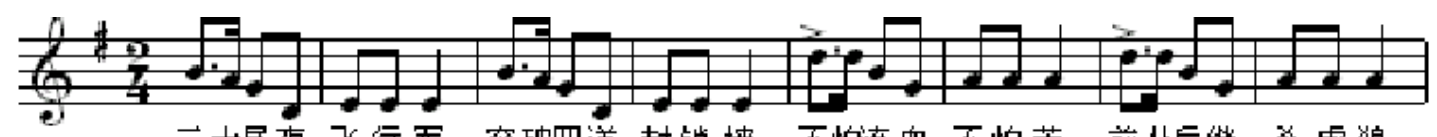

三十量变飞行军，突破四道封锁墙。不怕䖻血不怕苦，前忆后继杀虎狼口

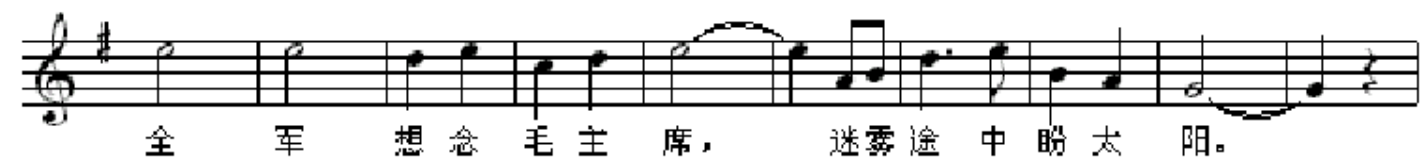

全军 想急毛主席, 迷雾途中䀡志阳。

“突破封锁”主题的素材是从“急行军”主题的内部重复并发展得来。其中在乐句中增加了经过 音装饰, 运用山东快书的节奏型, 构成了一个全新的乐节, 然后又进行了重复、不规则模进 再重复的发展, 生动地表现了红军再突破四道封锁线时激烈的战斗气氛。具有节奏结构上的 民族特色。《突破封锁线》全曲曲式结构为并置型二部曲式, 调式分布为 $\mathrm{G}$ 宫— 羽一 $\mathrm{a}$ 商 $-G$ 宫 $-D$ 徵一 $G$ 宫 $G$ 宫, 全曲体裁分布为进行曲。

\section{3 《遵义会议放光辉》}

《遵义会议放光辉》采用了选用贵州音调, 运用了贵州苗族与侗族的山歌中的音乐素材。“苗 岭秀, 旭日升”, 作曲家生茂特别提到这简单的和声中,有一处大二度延长三拍, 解决到纯四 
度, 是典型的苗族和声特色 6 。生茂采用苗族舞蹈的节奏型。

民歌素材苗族舞蹈的节奏型， Folk music (rhythm)：

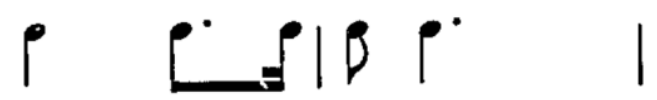

在此基础上创作出如下旋律, Theme rhythm:

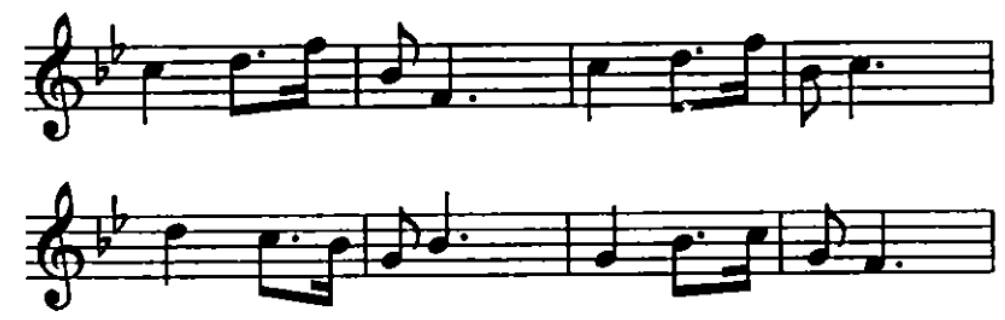

女声二重唱是徵调式, 段尾却转为民歌中常见的羽调式, 第二段苗族舞曲, 同一节奏型的徵 调式旋律（顾震夷.1999）。

苗岭主题, Alto duet, Theme Example 7:

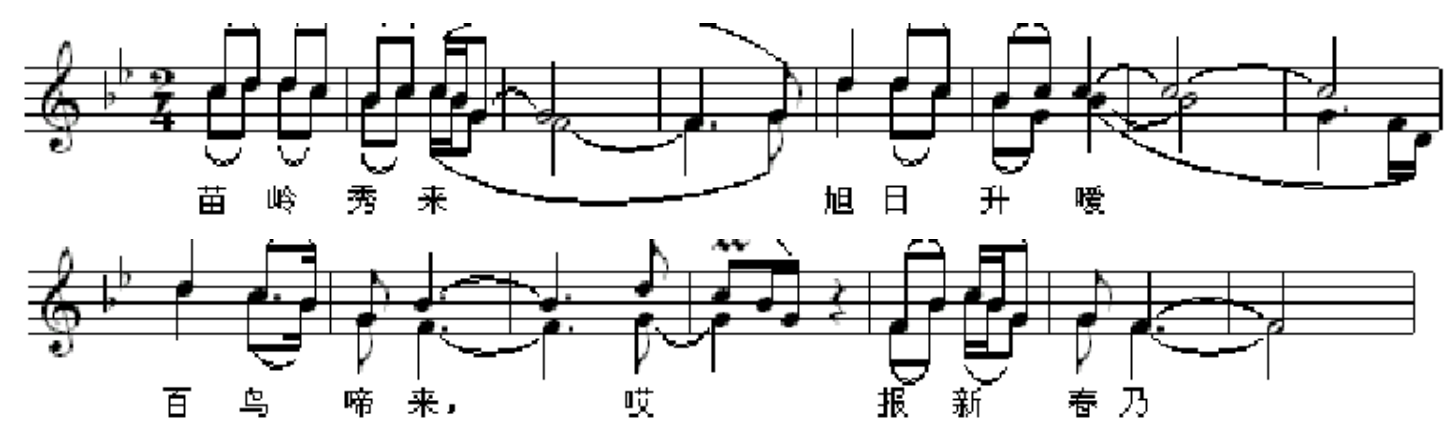

民歌素材《开天辟地》主题7, Folk music melody 5:
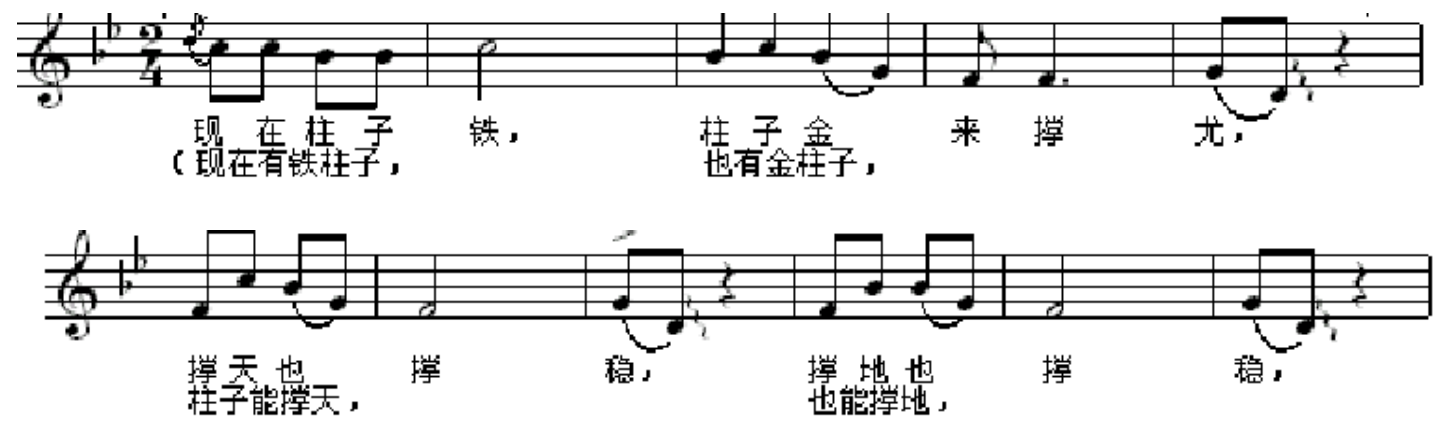

6顾震夷. 关于 《长征组歌》的音乐一一记生茂的一次谈话 [J]. 人民音乐, 1999 (08) : 24-26.

7乐谱引自中国音乐研究所编.苗族民歌[M].北京：人民音乐出版社, 1958.17. 

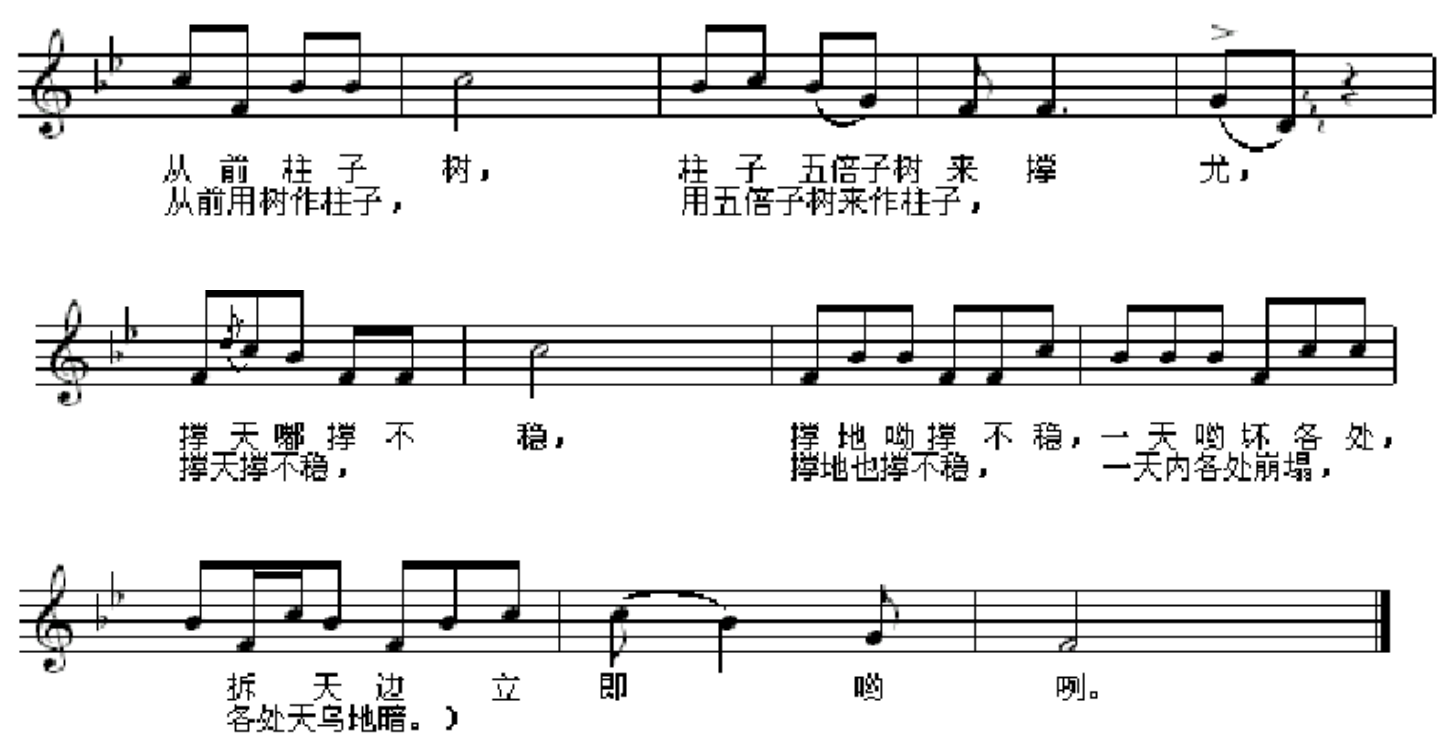

苗岭主题的前两小节为《开天辟地》主题的改编, 属于苗族音乐素材, 旋律发展在一个八度 之内, 速度舒缓起伏不大属于五声徵调式, 而苗族的古歌带有一些神秘的巫术气氛, 多为一 些叙事性的传说, 这一首则讲述了开天辟地的神话传说。在苗岭主题三四小节, 则运用了侗 族的音乐素材《蝉之歌》《小歌》以五声羽调式, 更具备抒情性旋律更富有张力。《遵义会议 放光辉》全曲曲式为合头换尾四部式曲式, 调性布局为 $\mathrm{b} \mathrm{B}$ 宫 $-\mathrm{F}$ 徵一 $\mathrm{g}$ 羽一 $\mathrm{F}$ 徵— $\mathrm{b}$ B 宫 -F，徵—b B 宫-G 宫 全曲体裁分布为综合性歌舞。 8,9

\section{4《四渡赤水出奇兵》}

根据现有文献和作曲家的谈他们的创造过程（顾震夷.1999）, 《四渡赤水出奇兵》采用了云 南花灯音乐。主题为羽调式, 是典型的云南花灯调式。在旋律发展上, “亲人送水”主题旋律 以级进为主, 具有云南花灯音乐的旋法特点。在节奏上, 基本采用了云南花灯音乐典型的节 奏特征。并在歌词中, 使用了祄词, 使节奏绵长旋律舒展。全曲曲式为合头换尾式四部, 全 曲调性布局为 $\mathrm{d}$ 羽 $\mathrm{F}$ 宫。全曲体裁布局为综合性歌舞。但是, 我们发现云南花灯作为地 方戏曲剧种, 由于各地语音有别和艺人演唱的不同, 地域性广及云贵川, 可分九个以上的支 派。我们研读和视奏了多达 30 多个谱例, 其民歌旋律一致接近, 接近符合, 或相似的, 暂 时没有发现, 多数花灯调里基本旋律都是向下级进或跳进, 自身带有羽调式的暗淡, 而四渡 赤水里采用了相同的节奏型, 但是旋律是向上的级进发展, 有一种活力奋发向上的感觉。所 以, 我们认为《四渡赤水出奇兵》是在花灯调的基础上进行创作的。顾震夷文指出, 作曲家 生茂的创作的确如此: “四曲《入云南》(后改名《四渡赤水出奇兵》) 用的是云南花灯, 这是 地方小戏(江南的小戏很多, 叫法不同, 江西叫“采茶”, 湖南叫“花鼓”, 贵州和云南叫“花灯”), 但不是原封不动的用。生茂使用民间音调主要应当 “神似” 而不能仅做到形似, 因为形似常 常不能表现新的我们需要的感情和场景, 这就要改造和提高”。

8唐诃, 晨耕. 长征组歌——《遵义会议放光辉》创作札记 $[J]$. 人民音乐, $1977(01): 60-62$.

9唐诃. 宣传长征 歌唱长征 继续长征一一谈谈《长征组歌》的音乐创作 [J]. 人民音乐, 1976 (05) : 29-33. 
按文献的提示思路, 我们试图还是想找出一首相近谱例, 我们觉得黄虎威 1958 年创作的钢 琴曲《乡村的节日》(melody 6 ), 钢琴谱有几个小动机是相似的。是不是传统花灯调需要确 认, 根据冯经纬和唐伟研究, 该作品的起始部分套用了《跳花灯》一段云南地区民歌的旋律。 显然民歌素材的直接来源具有一定的参考意义, 黄虎威在传统音乐基础上进行的再创作, 也 可能对后来的《长征组歌》创作产生了影响 ${ }^{10}$ 。至少, 《长征组歌》这段旋律和黄虎威的《乡 村的节日》，在民歌对音乐创造的影响，殊路同归。

我们最初的想象是《长征组歌》的几位创作者, 沿着当年长征路线进行了采风, 也许他们的 确发现有接近的民歌旋律素材, 只是目前文献和网络中找不到现有谱例。我们认为如此众多 地域民歌, 作为研究, 还是有待今后深入研究挖掘。杨志强在《 “苗疆” : “国家化” 过程 中的中国西南少数民族社会》一文中提起 “苗疆” 。明清时期, 广义的“苗疆”几乎涵盖了 整个云贵高原地区。“这一区域, 自古以来就是少数民族栖息分布之地, 现今除汉族外, 仍 有苗、侗、布依、彝、水、土家、瑶等近 20 个世居民族, 是中国民族种类最多、文化最多 样的区域”。

杨志强指出: 到了清代, “苗” 的指称范围进一步扩大到贵州全省及周边地区, 区域内大多 数少数民族的称谓以 “苗” 作为后缀, 如 “仲苗” (布依族)、“水家苗” (水族)、“洞 苗” (侗族) 等, 故而贵州省有 “百苗”之说。近代以后, “苗”进而取代 “蛮”涵盖了中国的 南方少数民族。.... 直至新中国进行民族识别以后, “苗” 才成为今天苗族的专称 ${ }^{11}$ 。

黄虎威《乡村的节日》, music (composition) melody 6:
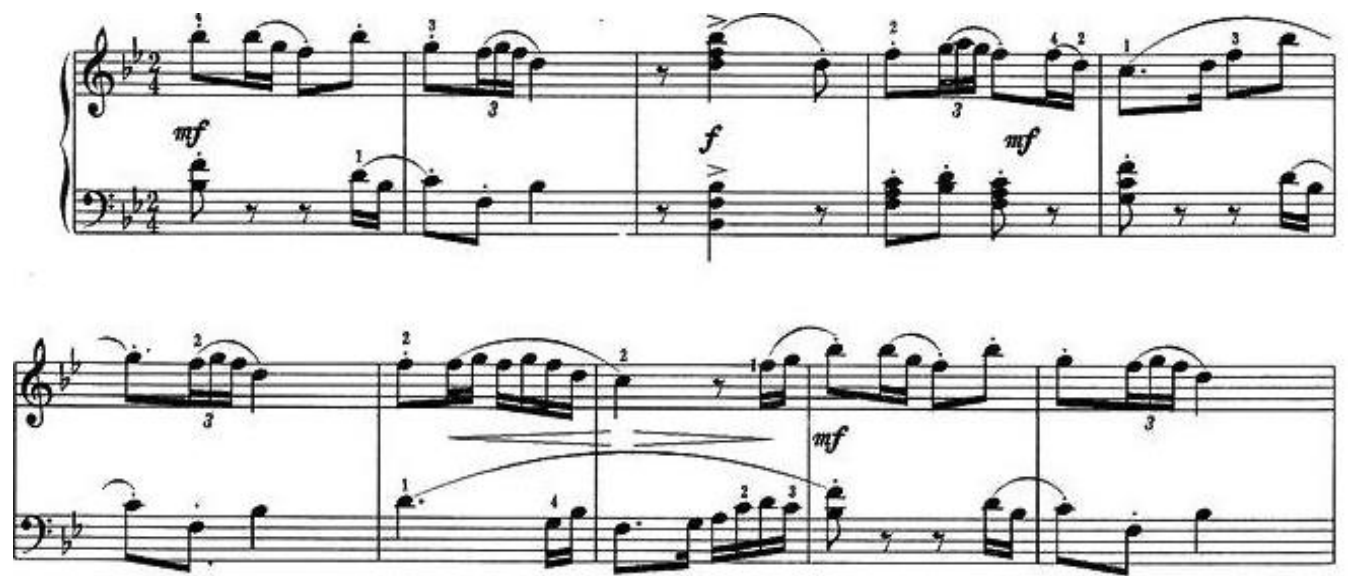

民歌素材《花灯调》节奏型, Folk music (rhythm) 7:

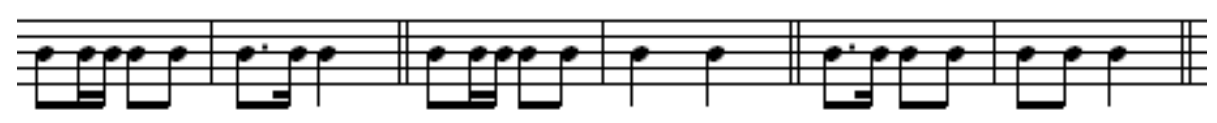

10冯经纬. 黄虎威《乡村的节日》艺术特征与演奏 [D]. 四川师范大学, 2018 (12)

11杨志强. 《“苗疆”: “国家化” 过程中的中国西南少数民族社会》 [N]. 中国民族报, 2018(01) 
出奇兵主题, Theme Example 8:

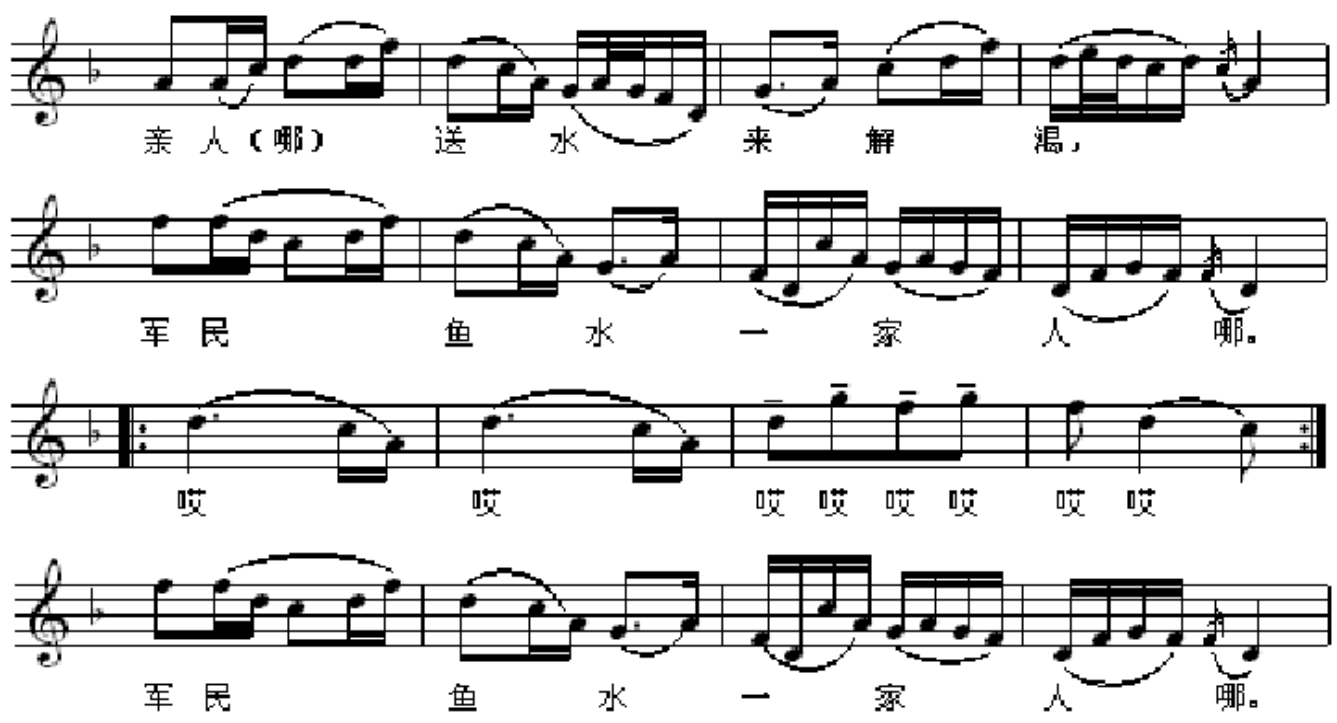

\section{5《飞跃大渡河》}

《飞跃大渡河》主要运用《见滩号子》中的典型节奏, 并贯穿全曲, 使其具有强烈战斗气息, 切分加附点节奏的运用更加突出了渡河这一主题。在调式上的创作以羽调式为主, 仅仅出现 过一次的变音为变宫, 其主要作用为经过性的装饰。在旋律上以级进为主, 旋律进行上增加 重复音, 与见滩号子旋律写作特征相同。此外, “渡河” 主题还吸收川江号子乐句短小的特 点, 精干有力, 便于多次重复。因此, “渡河” 主题具有明显的川江号子特点, 形象地表现 了红军强调大渡河时激烈的战斗, 体现了红军战士不畏艰难, 勇往直前的精神。《飞跃大渡 河》全曲采用并置型二部曲式, 调性布局为 b B 宫 $-F$ 宫 $-C$ 宫, 全曲体裁为船工号子。作 曲家提出: “整个歌曲用船工号子高元的长音和短促的 “咳” 开头, 接着用坚定有力的划船 节奏”（顾震夷.1999）。

民歌素材划船节奏, Folk music (rhythm) 7:

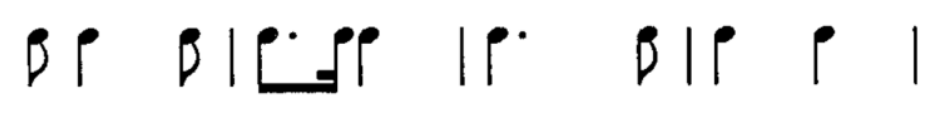

渡河主题, Theme Example 9:

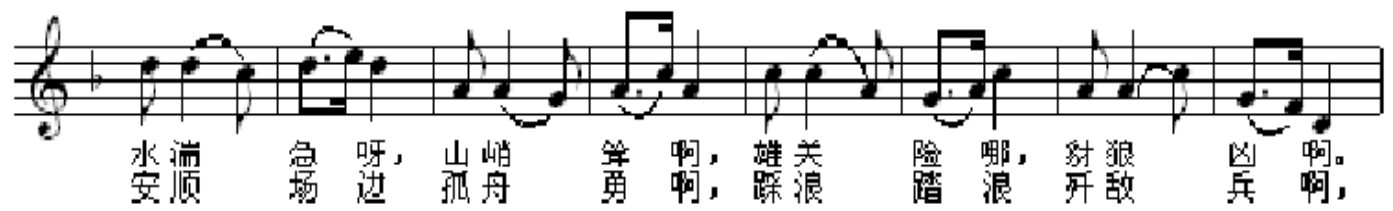


民歌素材《滩号子》主题, Folk music (melody) 7:
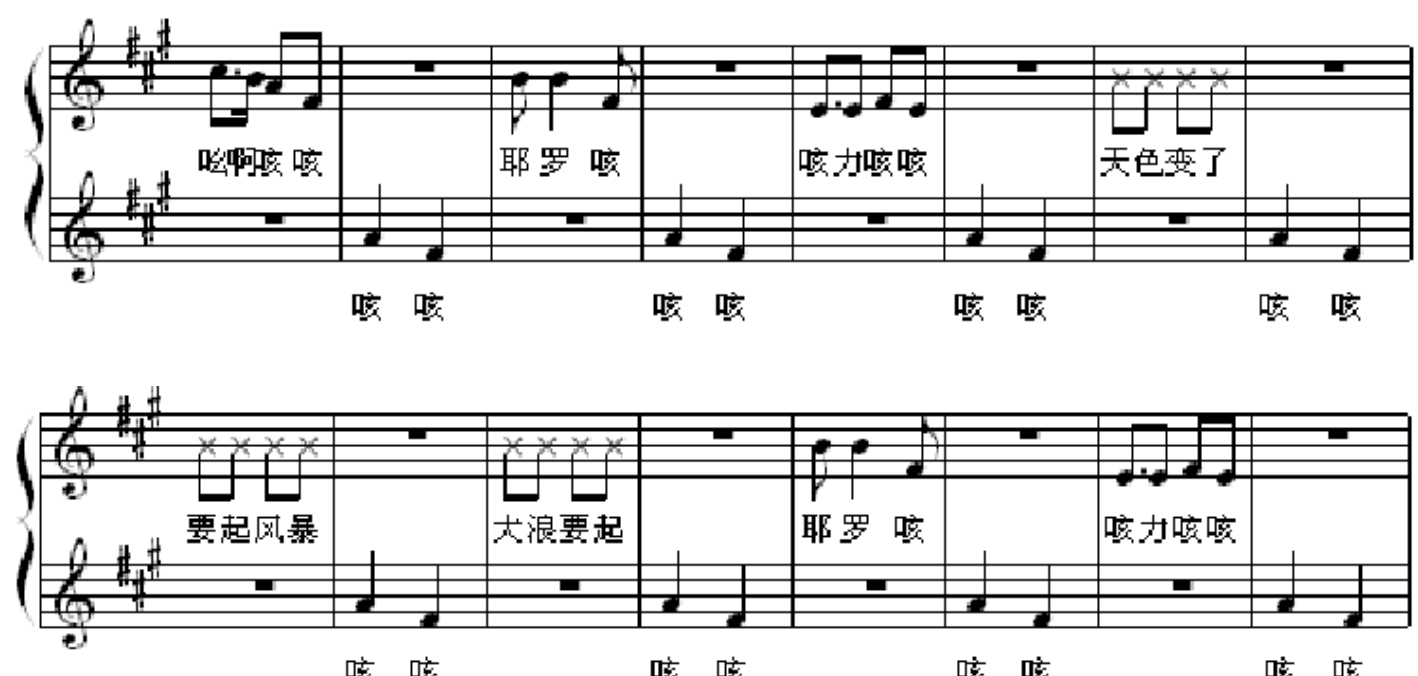
咳 咳
咳 咳
咳 咳
咳 咳
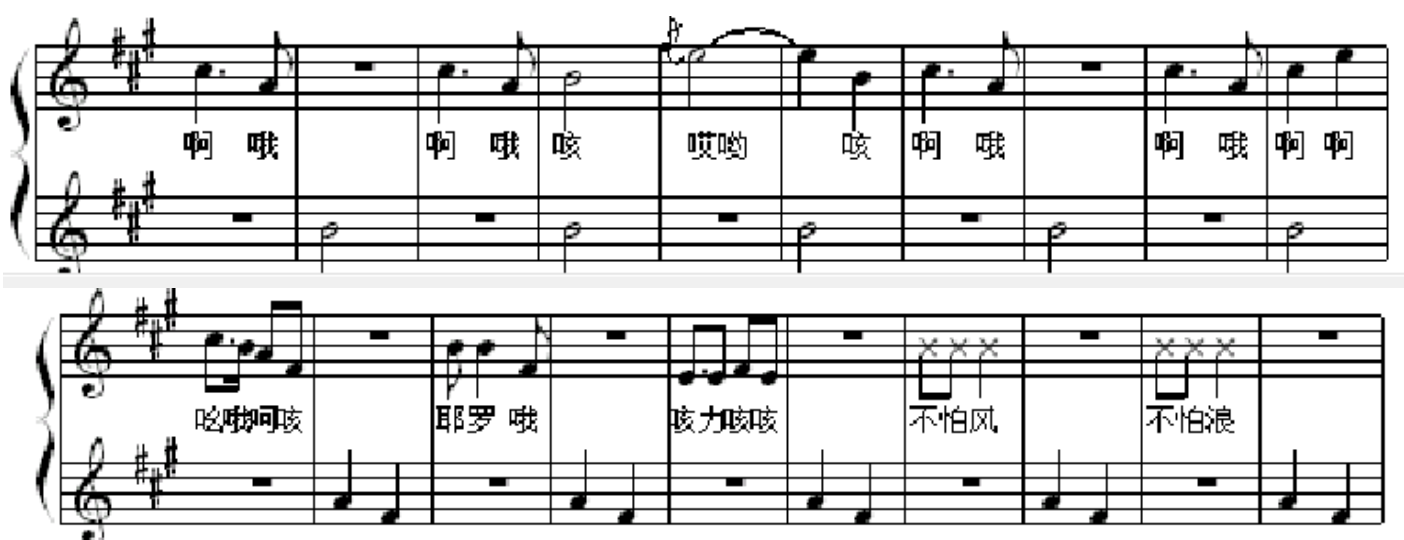

咳咳

咳咳

咳咳

咳咳

咳 咳

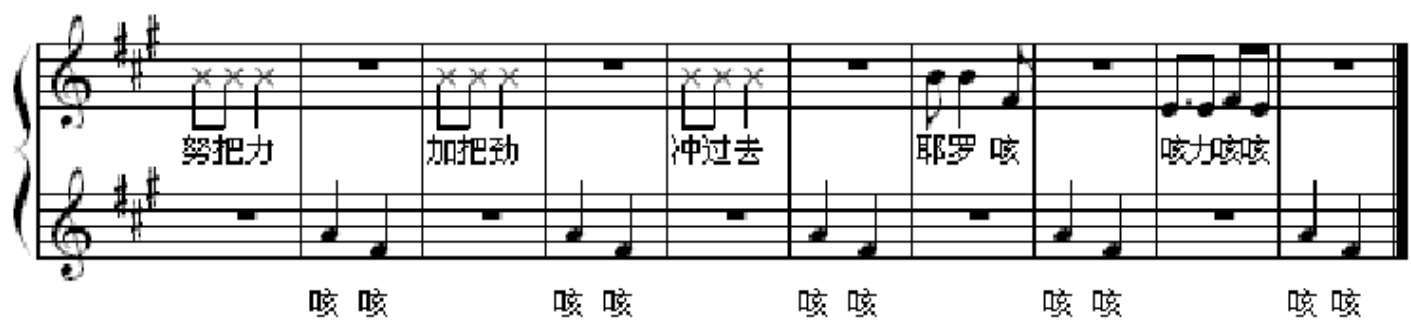

6《过雪山草地》

《过雪山草地》中有一段同名独唱乐曲, 是本作品中最为受观众喜爱的一段男高音独唱, 主 要运用了青海藏族歌舞《小小的鸟儿》的音乐元素。 
过雪山草地主题(Aria for tenor) Theme Example 10:
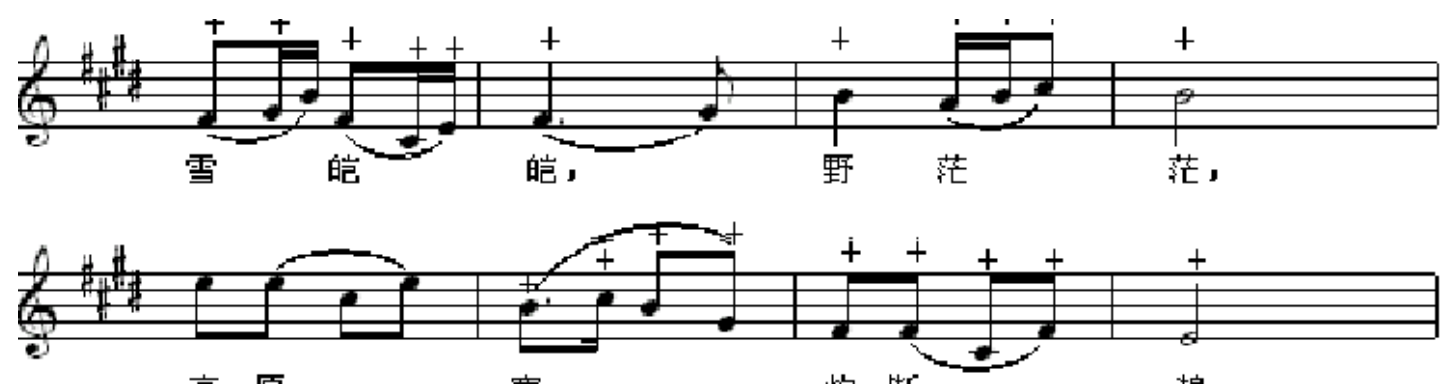

高原寒，焰断

粮。
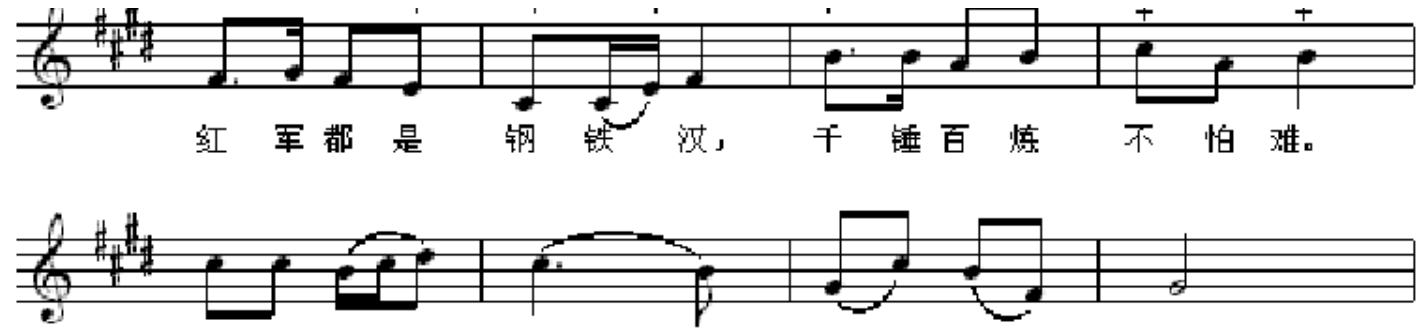

雪 山 低

头

迎

客,

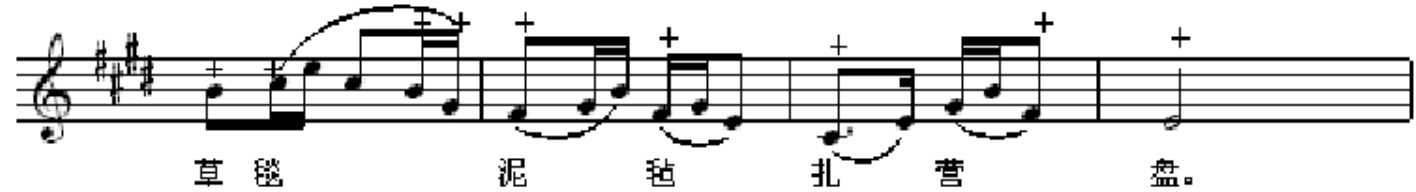

民歌素材《小小的鸟儿》12, Folk music (melody) 8:
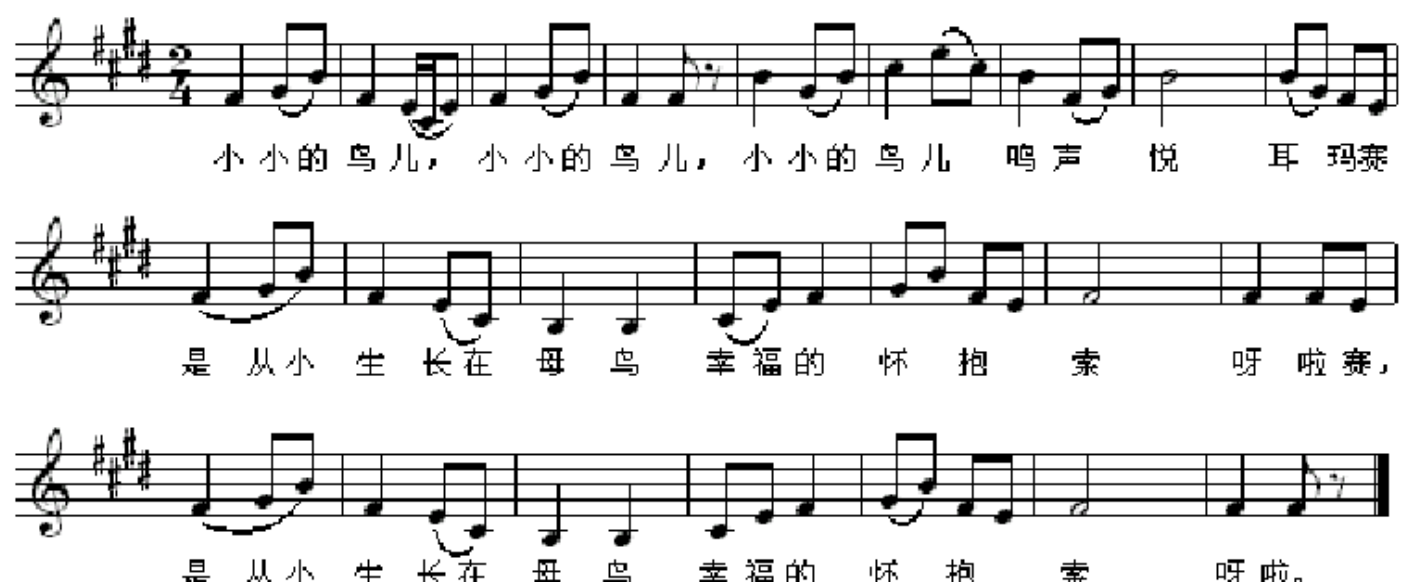

《过雪山草地》主题由五个乐句组成, 其音乐的主题动机来源于 《小小的鸟儿》, 旋律为环 绕商音进行, 由于节奏的律动性被拉长, 使旋律较比《小小的鸟儿》更具有抒情性。《过雪 山草地》全曲为并置型二部曲式, 全曲调式分布为 $\mathrm{d}$ 羽- $\mathrm{c}$ 羽- $\mathrm{E}$ 宫 $\mathrm{F}$ 宫 $-\mathrm{E}$ 宫 全曲体 裁分布为抒情曲。

12乐谱引自《中国民间歌曲集成》全国编辑委员会, 《中国民间歌曲集成・青海卷》编辑委员会编.中国民间 歌曲集成・青海卷[M].北京: 中国 ISBN 中心, 2000.450 . 


\section{7 《到吴起镇》}

《到吴起镇》序奏中充满浓郁陕北风味的 “陕北民风” 主题是采用陕北绥德秧歌《偷南瓜》 改编的。

到达陕北主题, Theme Example 11:

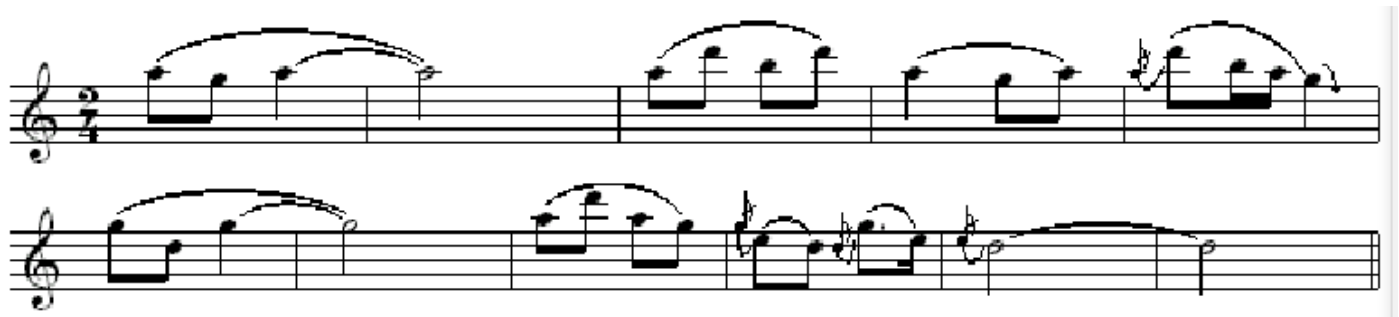

民歌素材《偷南瓜》主题13, Folk music (melody) 9:

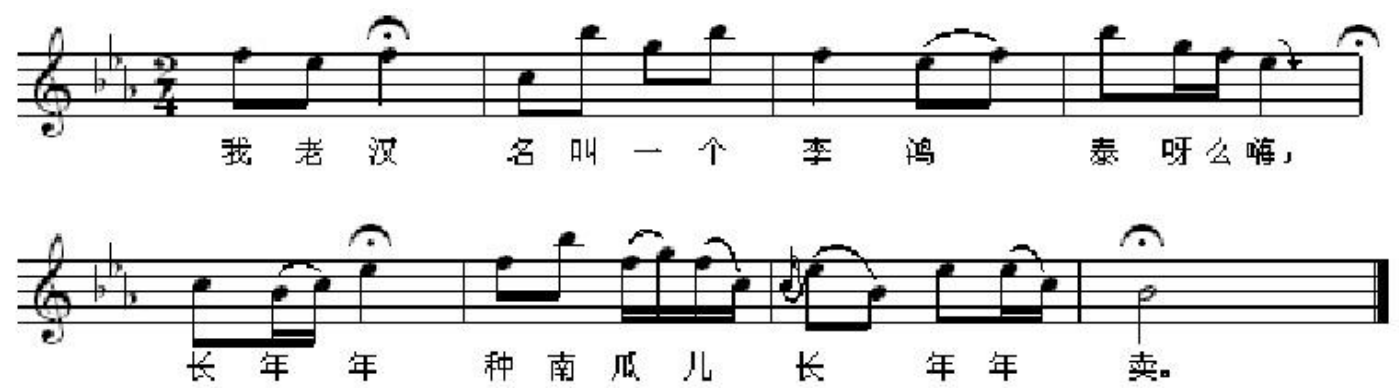

《到吴起镇》主题的创作基本符合《偷南瓜》的旋律写作，在整体的旋律发展中整体向上移 高三度, 而在山歌的自由性创作中将延长记号的即兴变为规整的三拍（四分音符加二分音 符), 在陕北民歌中, 非常多的会运用到多度数的跳进, 在《偷南瓜》中分别在第二小节运 用上行七度的跳进，第六小节下行四度的跳进以及第七小节向下五度的跳进。频繁的跳进与 当地的地理因素有着千丝万缕的联系, 同时也是对当地人的生活状况的一种直观的反馈。频 繁的跳进进行可以表达了一种恳切的情绪。在《到吴起镇》的主题旋律中, 同样也是运用了 这样的创作手法, 表达了当地人对红军最热切地盼望, 同时也传递出当地人民的质朴。

欢庆陕北主题, Theme Example 12:

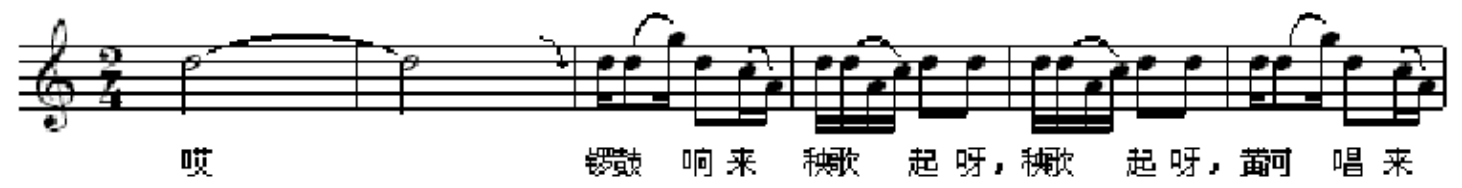

13 乐谱引自《中国民间歌曲集成》全国编辑委员会, 《中国民间歌曲集成・陕西卷》编辑委员会编.中国民间 


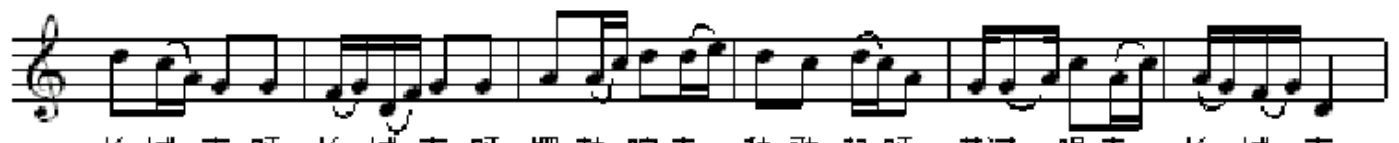

长城喜呀，长域喜呀。罗㗝响来积歌起呀，黄河唱来长城喜。

节奏上, 吸取了陕北秧歌切分节奏与正规节奏相结合的节奏特征。而通常小切分加十六分音 符的快速节奏, 更能体现出陕北热烈欢腾的情景。这也是由之前, 到达陕北主题与欢庆陕北 的主题的明显节奏区别。前期节奏趋于平稳旋律无明显大跳进, 而后期节奏鲜明旋律明朗。

《到吴起镇》全曲正反合三部曲式, 调式布局为 $\mathrm{D}$ 徵一 $\mathrm{d}$ 商 $\mathrm{C}$ 宫，体裁分布属于综合 性歌舞。

\section{8 《祝捷》}

《祝捷》在民歌体裁中运用湖南花鼓戏表达了战争胜利时的喜悦。在旋律上通过改变音高, 此主题的素材来源于长沙花鼓戏“双川调”的上句过门。

祝捷主题, Theme Example 13:

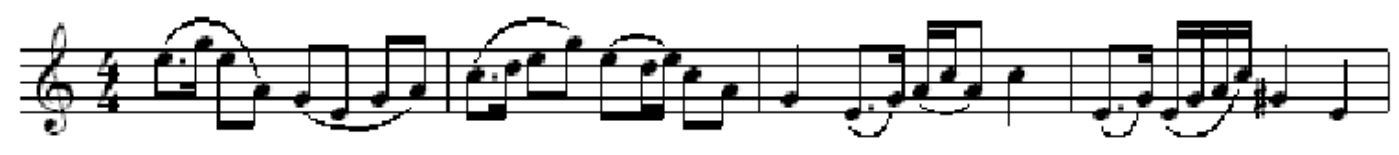

民歌素材《双川调》过门主题 ${ }^{14}$, Folk music (melody) 10:

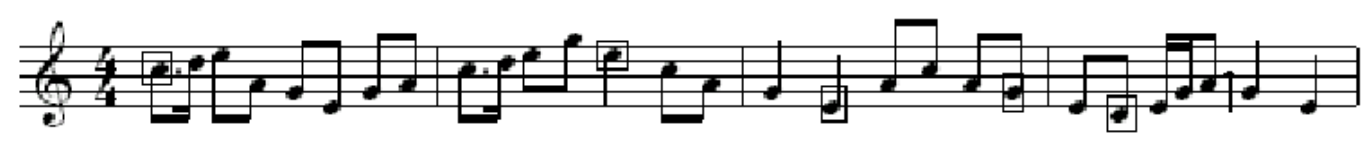

川调是湖南花鼓戏的主要声腔, “双川调” 是川调中最常见的形式, 由 “上句过门十上句唱腔 —下句过门十下句唱腔”四个部分构成。上例是长沙地区花鼓戏“双川调”的上句过门, 它 来源于湘潭地区的山歌, 曲调起伏跌宕, 悠扬活泼富有风趣, 其中结尾的微升徵音具有典型 的湖南音乐特点。同样, 在《祝捷》主题中最后一小节的 $\mathrm{g}$ 也升高半音。《祝捷》全曲为板 腔体曲式, 调性分布为 $\mathrm{g}$ 徵一 $\mathrm{a}$ 羽 $\mathrm{C}$ 宫 全曲体裁分布戏曲风唱段。

\section{9 《报喜》}

《报喜》所采用的民歌素材为赣东北地区的采茶戏《思怀》为创作的主要动机。

14乐谱引自湖南省戏曲工作室编.刘海砍樵[M].长沙：湖南人民出版社, 1960.4 . 
报喜主题, Theme Example 14:

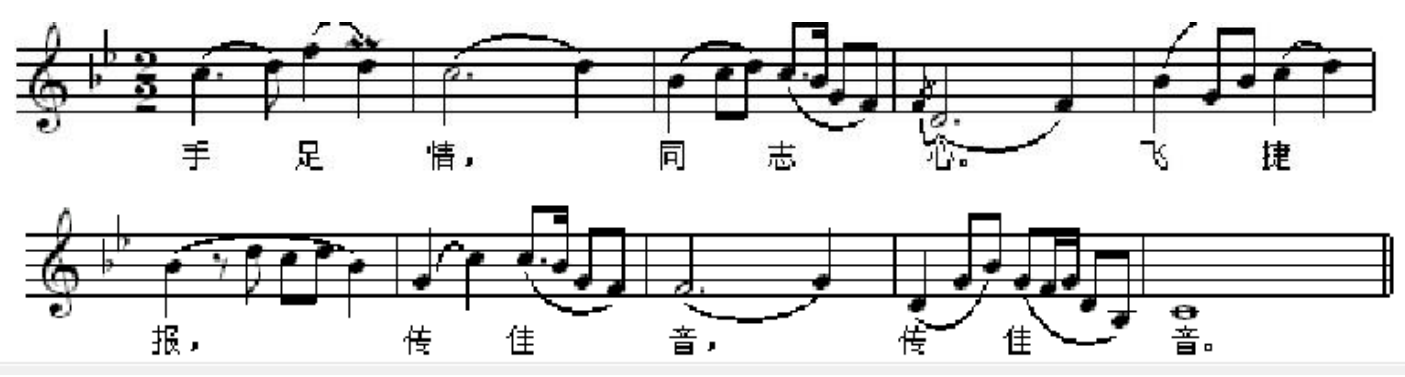

民歌素材《思怀》 ${ }^{15}$, Folk music (melody) 11:

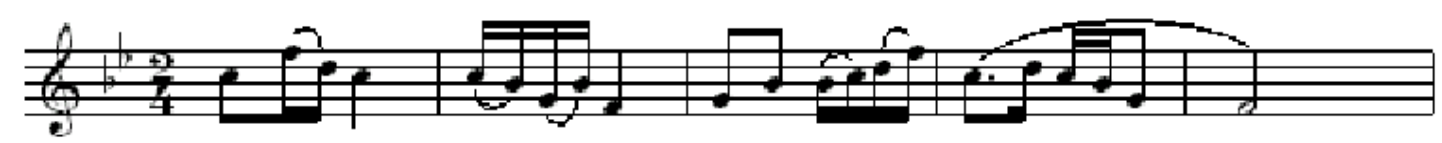

清早起百花开妐娱得了喂
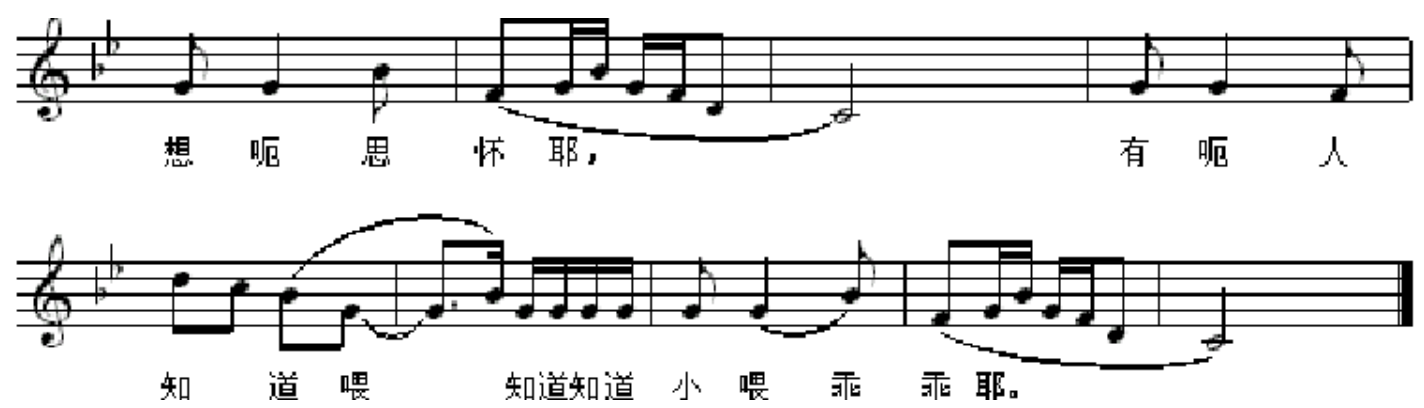

《报喜》主题在《思怀》三脚调节奏基础上, 更为舒展, 旋律基本采用了其创作手法, 但在 情感上由戏曲中小情小爱转为手足情, 在情感的转变中更能突出主题。《报喜》全曲曲式为 板腔体, 调性布局为 $\mathrm{c}$ 商 b B 宫 全曲体裁分布为戏曲风唱段。

\section{$10 《 大$ 会师》}

《长征组歌》由于采用了诸多民歌素材, 复合民族性审美。技术上, 仍然具有一定的西洋音 乐的定式和规范, 或模式, 我们以第一乐章和《告别》和最后乐章《大会师》为例, 简单地 阐述我们的观点。

《大会师》的前奏是在再现《告别》的基础上展开的。《告别》和《大会师》引子小号旋律 基本相同（Theme Example 15 和 16)。, 《大会师》第一小节第四拍和第一拍, 第二拍和声 色彩进行了不同处理 (Theme Example 15 和 16 红框)。

15 乐谱引自上饶专区采茶剧团编.赣东北采茶戏音乐[M].南昌: 江西人民出版社, 1959.39 . 
《告别》引子旋律 Introduction of movement 1. Theme Example 15:
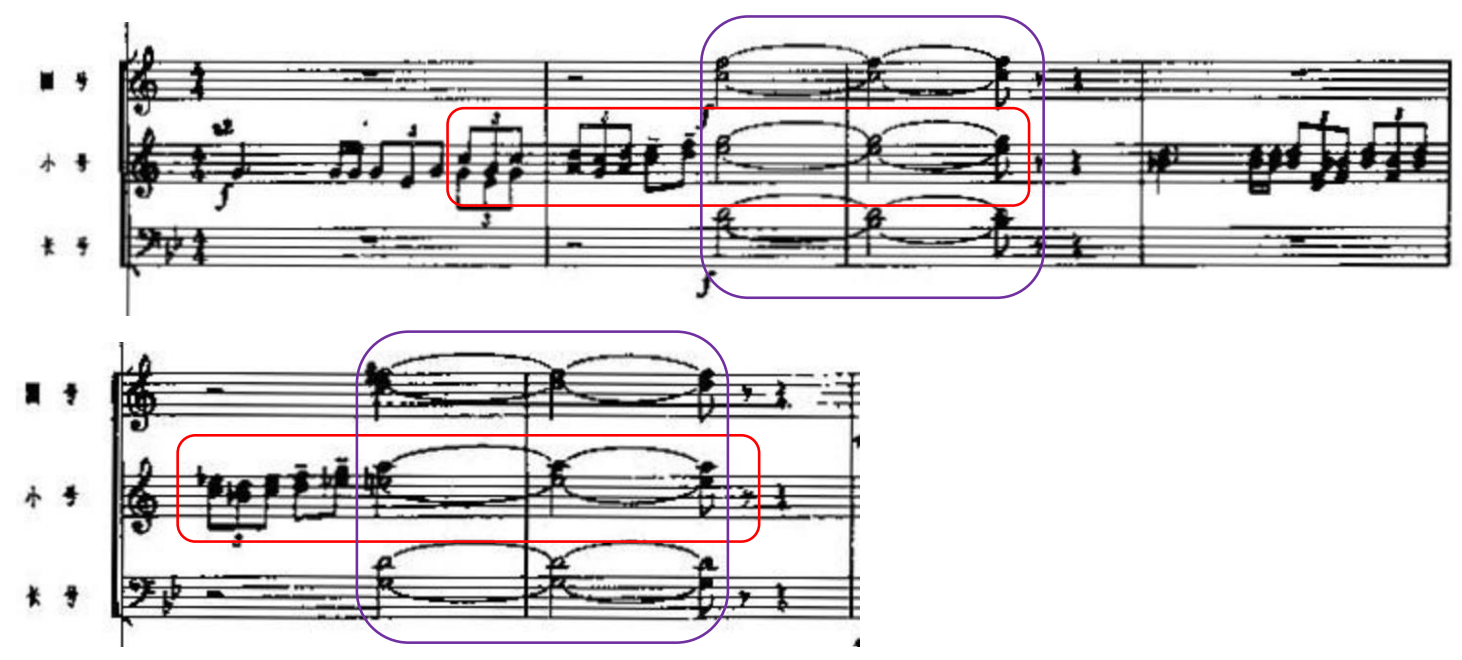

《大会师》引子旋律 Introduction of movement 10. Theme Example 16:

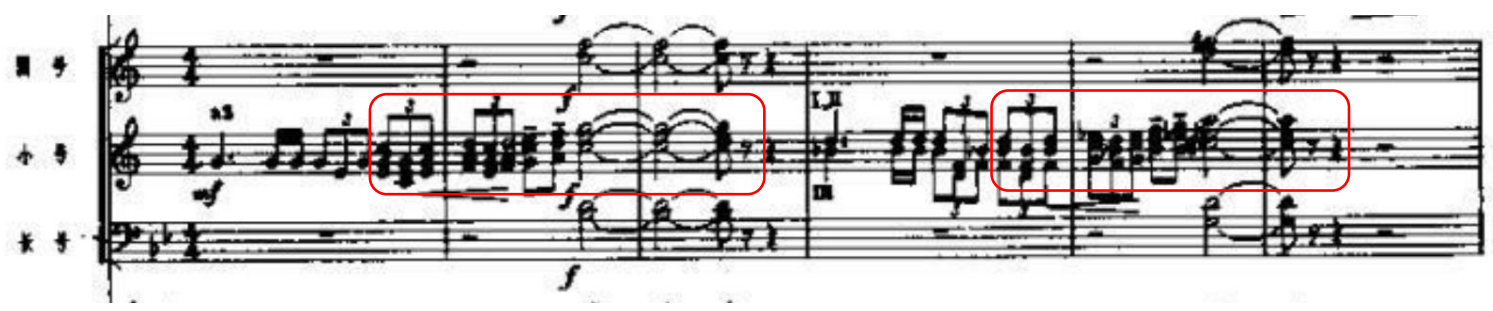

《大会师》合唱“啊”乐段, Theme Example 17:
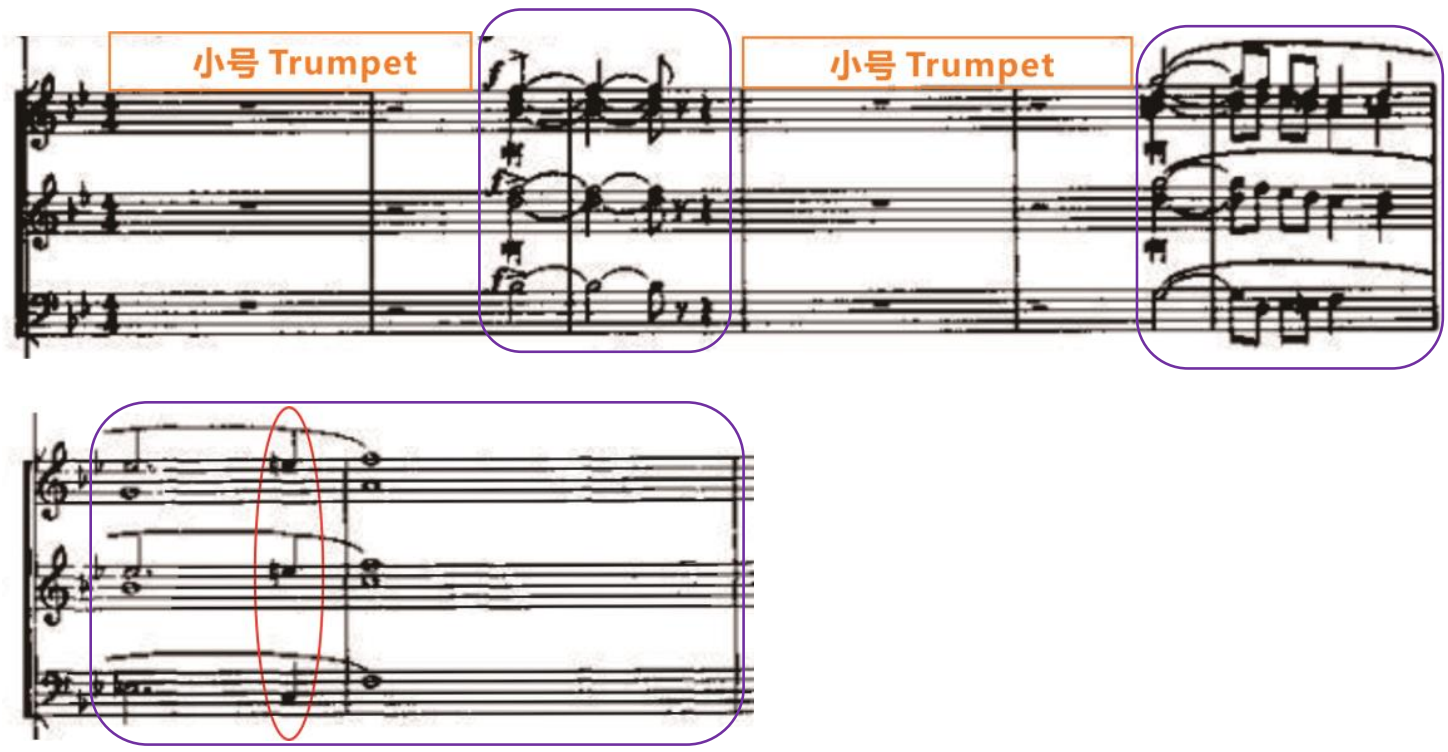

引子过后, 对比前面各乐章, 作为最后一个乐章《大会师》, 开始的调性和小号的应用以及

“红旗飘, 军号响” 歌词, 和第一乐章《告别》有呼应和再现的音乐情绪(对比 Theme Example 
15 和 16 红框)。《大会师》引子小号后面的 “啊” 合唱 (Theme Example 17 褐色方框) 是《告 别》的引子和声出现色彩变化后, 紧跟着以声乐合唱 “啊” 加入原来只有器乐乐队全奏旋律 (对比 Theme Example 15 和 17 紫色框)。呈现一个力度很强无词祄字合唱, 体现明快地音 乐情绪变化, 使得一直以民歌旋律为基调的音乐模式进一步发展演化, 旨在展现新的音乐形 象。从第一句 $\mathrm{F}$, 再与小号呼应, 到第二乐句 $\mathrm{G}$ 经过连续下降级进到 $\mathrm{b} E-\mathrm{tE}-\mathrm{F}$, 由此形成 F-G-F-bE-D-C-D- $4 E-F$ 下行模进经过一个小二度（Theme Example 17 椭圆框）到终止。

《大会师》在旋律创作中, 我们没有发现过多的运用到各地具体的民歌的素材, 而在配诗朗 诵部分的旋律采用了结构缩减的《红军胜利歌》, 这是根据创新的音乐材料的需要去掉原民 间痕迹中多余的材料，使这段结构更加精干紧凑。《红军胜利歌》谱写了红军第四次反 “围 剿” 的伟大胜利, 在军歌中占有很重要的地位, 该曲为单二部曲式, $\mathrm{A}$ 段旋律明朗, 节奏明 快, B 段中节奏坚定但旋律发展耐人寻味, 两个乐句在重复中互相颠倒。

胜利主题, Theme Example 18:

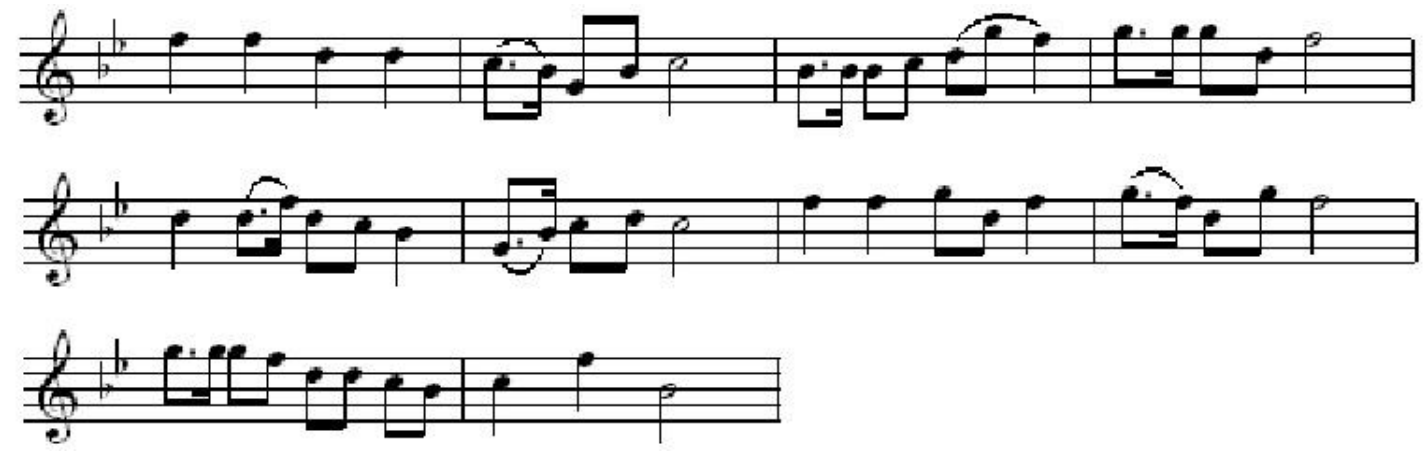

红军歌曲《红军胜利歌》16, 17 Folk music (melody) 12:

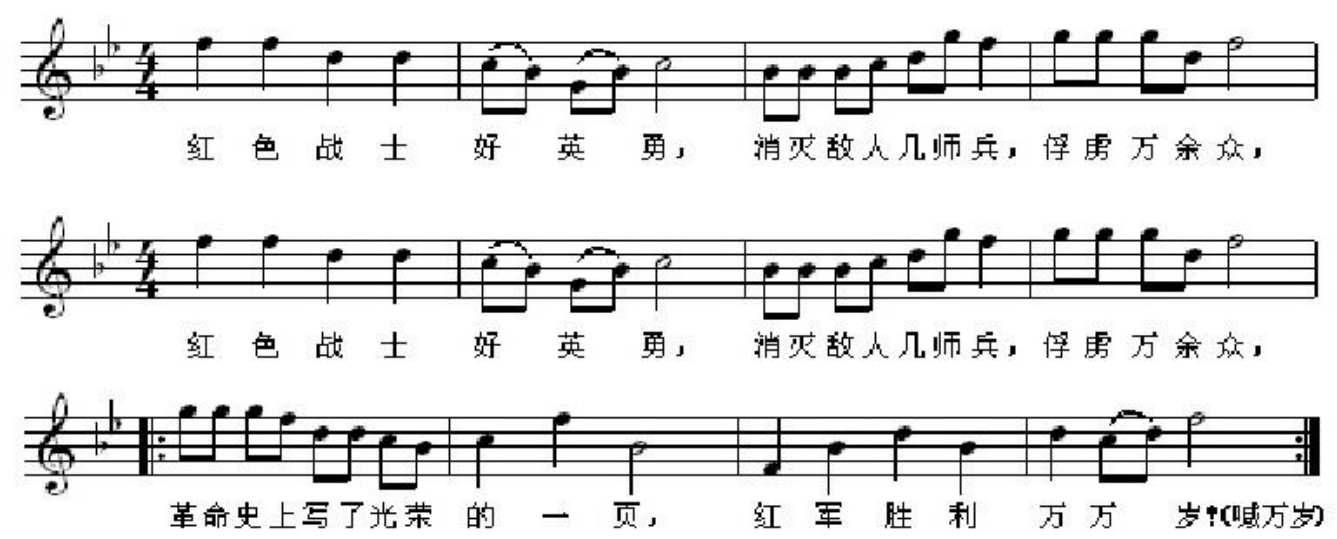

《大会师》胜利主题为五声性的音调, 降 B 宫调式具有民族特点, 并且旋律在 D 音上开始,

16 乐谱引自解放军歌曲选集编辑部.中国工农红军歌曲选[M].内部业务参考资料, 1954.10.

17 乐谱引自解放军歌曲选集编辑部.中国工农红军歌曲选[M].内部业务参考资料, 1954.10. 
由于角音作为始音, 让人感到亲切, 且最后落在主音宫音上, 是中西方音乐文化的融合, 更 展现出大会师的意义所在。由于缩减架构导致《红军胜利歌》结尾处的不稳定趋向于稳定, 这也是西方作曲中常见的写作手法。

大会师“红旗飘，军号响”再现主题, Theme Example 19:

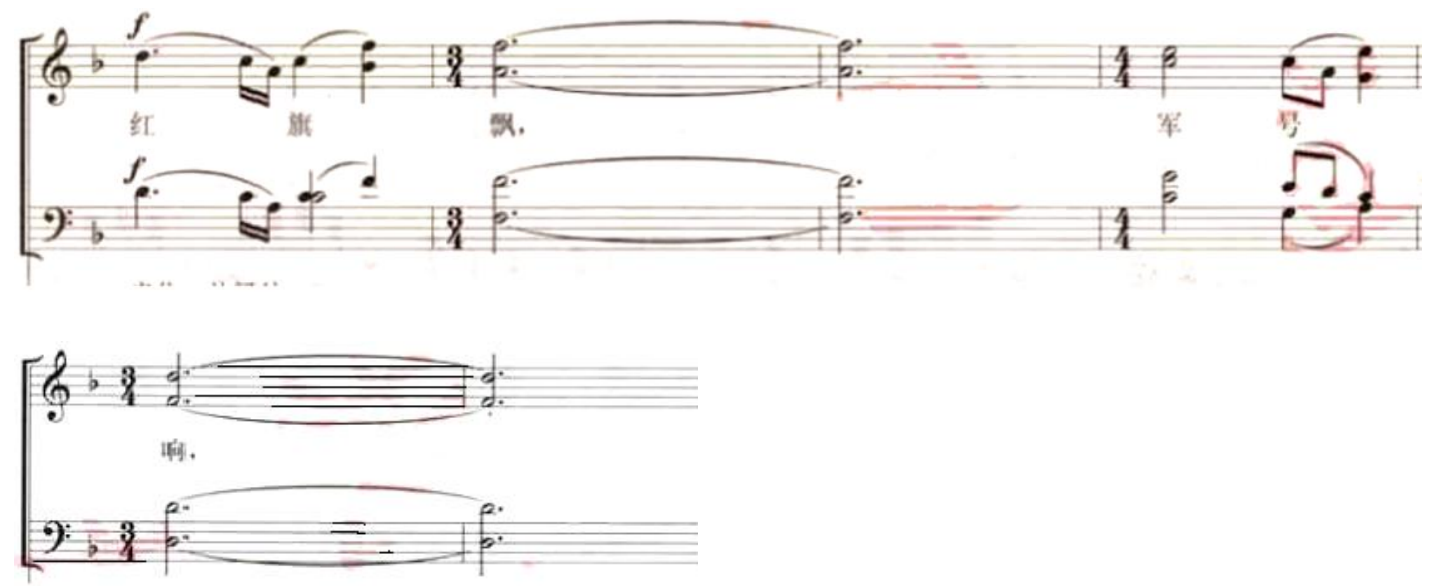

对比《告别》上征途“红旗飘, 军号响”主题, Theme Example 20, (Ibid. Theme Example 1):

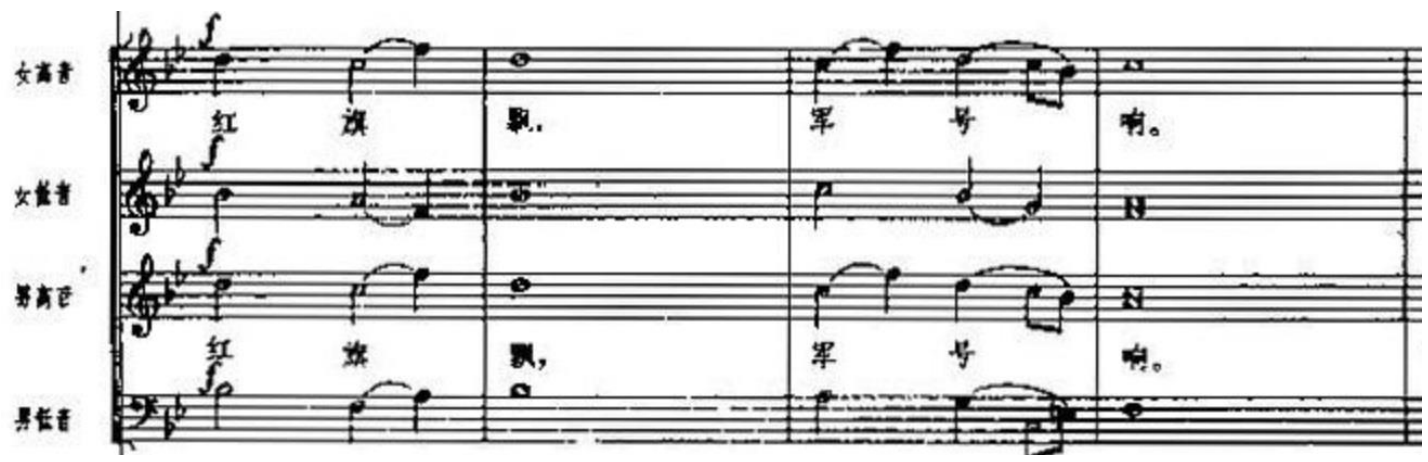

《大会师》主题变化再现了《告别》的大部分主题, 增强了整部作品的统一性, 使分曲之间 凝结成一个有机的整体。同时, 再现中的变化发展, 旋律做了相应的跳进 (对比 Theme example 19 和 20），节拍由原来单一的 $4 \mid 4$ 拍变化发展为 $4|4 ， 4| 3 ， 4 \mid 4$ 交替节拍，节奏也使原来告别 情绪一下子变成了激动, 兴奋, 激昂的情绪。各分曲中由于情绪的转变, 也证明了统一性中 的对比性, 使整体作品在保留完整的统一性中不失个性的凸显。全曲调性布局为 b B 宫一 $\mathrm{C}$ 徵一F 宫一b B 宫, 曲式结构为并置型四部, 体裁分布为叙事性终曲。

最后的尾声结束句, 共产党的“产”有一个三连音 (Example 21 红框), 这是民歌中比较少见, 也是作品唯一的声乐旋律中唯一的三连音, 也靠近西方作曲手法。 
尾声结束句旋律 (Example 21, Coda in the movement 10):

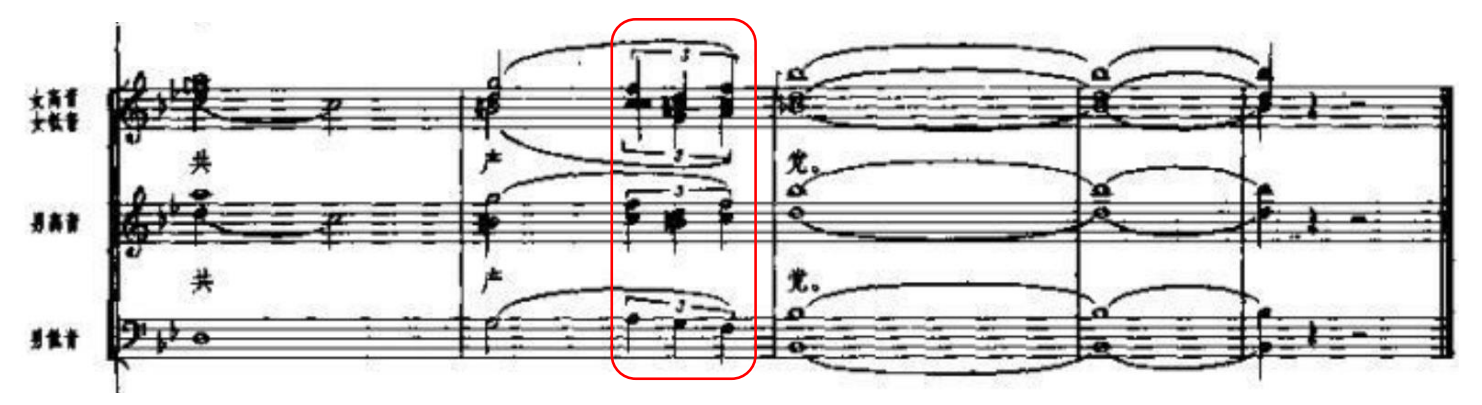

总结:

中国的民族民间音乐有着深厚的历史传统。由于复杂多变的自然环境和博大的文化背景, 使 音乐不是孤立的, 而是整个民族文化有机的组成部分。一部优秀的作品须植根于民族性创作,

《长征组歌》有效的运用了多地区多民族的音乐元素, 采用民歌作为最原始的旋律主题动机, 进行编创, 这也为它的成功奠定了基础。配器方面, 在管弦乐队基础上, 加入了二胡, 三弦, 笛子, 唢呐和快板等民族乐器, 在重要的乐段场景, 笛子还担任独奏, 唢呐和快板在特定乐 段一定程度上, 发挥了主导器乐角色。总体上, 民歌风和民乐贯穿于整个的作品, 民族声乐 和西洋美声, 民乐和西洋交响乐队达成了相互融合。在当今的舞台上, 活跃着多元文化系统, 有东方的也有西方的, 包括了世界多民族的多种时代背景和多种层次风格体裁的音乐作品, 无论在哪个时代下，只有民族的才是世界的。

利益冲突声明:

不存在版权冲突, 不存在与我工作职责相冲突的任何个人经济利益或非经济利益以及任何直 接或间接的义务和责任。

\section{参考文献:}

[1] 石祥, 萧华与《长征组歌》 [N].解放军报 (长征副刊), 2016 (9) - 11

[2] 乐谱引自解放军歌曲选集编辑部.中国工农红军歌曲选[M].内部业务参考资料, 1954.19 .

[3] 参见李双江主编.中国人民解放军音乐史[M]. 北京: 解放军文艺出版社, 2004 .

[4] 乐谱引自《中国戏曲音乐集成》全国编辑委员会, 《中国戏曲音乐集成. 江西卷》编辑委员会编.中国戏 曲音乐集成·江西卷[M].北京: 中国 ISBN 中心，1999.1860-1861

[5] 乐谱引自《中国戏曲音乐集成》全国编辑委员会, 《中国戏曲音乐集成.江西卷》编辑委员会编.中国戏 曲音乐集成·江西卷[M].北京: 中国 ISBN 中心，1999.1827-1828.

[6] 顾震夷.关于《长征组歌》的音乐——记生茂的一次谈话[J].人民音乐,1999(08):24-26.

[7] 乐谱引自中国音乐研究所编.苗族民歌[M].北京: 人民音乐出版社, 1958.17 .

[8] 唐诃,晨耕.长征组歌——《遵义会议放光辉》创作札记[J].人民音乐,1977(01):60-62.

[9] 唐诃.宣传长征 歌唱长征 继续长征一一谈谈《长征组歌》的音乐创作[J].人民音乐, 1976(05):29-33.

[10] 冯经纬. 黄虎威《乡村的节日》艺术特征与演奏 [D].四川师范大学,2018(12) 
[11] 杨志强. 《“苗疆”: “国家化”过程中的中国西南少数民族社会》 [N].中国民族报,2018(01)

[12] 乐谱引自《中国民间歌曲集成》全国编辑委员会，《中国民间歌曲集成. 青海卷》编辑委员会编.中国民 间歌曲集成·青海卷[M].北京: 中国 ISBN 中心，2000.450.

[13] 乐谱引自《中国民间歌曲集成》全国编辑委员会，《中国民间歌曲集成. 陕西卷》编辑委员会编.中国民 间

[14] 乐谱引自湖南省戏曲工作室编.刘海砍樵[M].长沙: 湖南人民出版社, 1960.4 .

[15] 乐谱引自上饶专区采茶剧团编.赣东北采茶戏音乐[M].南昌: 江西人民出版社，1959.39.

[16] 乐谱引自解放军歌曲选集编辑部.中国工农红军歌曲选[M].内部业务参考资料, 1954.10.

[17] 唐艺华 《长征组歌》音乐创作民族化研究 [D]. 南京艺术学院 2008

Supplemental materials:

1. 长征组歌, https://zh.wikipedia.org/wiki/长征组歌

2. 李遇秋, 《长征组歌》创作始末, http://www.yhcqw.com/34/928.html

3. 一捧花生 一碗米酒 都是老区情怀，北京晚报 2016,8,24.

http://www.bjskpj.cn/changzheng/172-czwenyi/4576-2016-10-16-14-18-21

4. 王琪鹏，《长征组歌》第二部分：用节奏感展现血战沙场，北京晚报 http://www.bjskpj.cn/changzheng/172-czwenyi/4637-2016-10-27-12-03

5. 《长征组歌》第三部分：红军的高兴劲儿 这样欢快唱出来, 北京晚报 http://www.bjskpj.cn/changzheng/172-czwenyi/4650-2016-10-31-02-47-15

6. 长征组歌》第四部分, 北京晚报. 延伸阅读: 周总理对《长征组歌》做了哪些修改? http://www.bjskpj.cn/changzheng/172-czwenyi/4667-2016-11-01-04-09-14

7. 王琪鹏，《长征组歌》第五部分，《长征组歌》为何能够成为经典? 董梦知， http://www.bjskpj.cn/changzheng/172-czwenyi/4706-2016-11-07-06-28-02

8. 王琪鹏, 《长征组歌》第六部分：逆境中高唱革命理想，北京晚报 http://www.bjskpj.cn/changzheng/172-czwenyi/4750-2016-11-14-03-02-54

9. 王琪鹏, 《长征组歌》第七部分：敲锣打鼓迎红军，北京晚报 http://www.bjskpj.cn/changzheng/172-czwenyi/4788-2016-11-17-14-04-51

10. 王琪鹏，《长征组歌》第八部分：革命完成奠基礼，北京晚报 http://www.bjskpj.cn/changzheng/172-czwenyi/4786-2016-11-18-01-53-33

11. 《长征组歌》谱集, http://www.qupu123.com/album/changzheng/

12. 长征组歌・红军不怕远征难 (1965 年首演录音) https://www.xiami.com/album/1577163493

13. Chorus suits Long March, https://www.youtube.com/watch?v=u1a0Mjss15M\&t=982s 
Appendix A

Long March Cantata was composed by Chen Geng (晨耕)、Sheng Mao(生茂)、Tang Ke(唐轫) and Yu Qiu (遇秋) in 1965. Movements with the soloists according to the premiere in 1965 and performance duration(min).

1 Leave the Base Area; Chorus, 7:19

2 Breaking the Blockade; Chorus, 2:44

3 The Zunyi Meeting, the Brilliance; Soprano Duet: Geng Lianfeng; Yang Yiran, Chorus, 6:01

4 Crossing Chishui River Four Times; Bass: Ma Guoguang, Soprano 1: Wang Bohua, Chorus, $7: 58$

5 Crossing the Dadu River; Chorus, 3:54

6 Climbing Snowy Mountains and Crossing Swamp Land; Tenor Jia Shijun, Chorus, 9:10

7 Arriving at Wuqi Town; Chorus, 5:21

8 Celebrating the Victory; Tenor 2: Wang Kezheng, Chorus, 4:39

9 Annunciation; Soprano 2, Soloist: Ma Yutao, Chorus, 4:44

10 Union of Forces; Chorus, 4:27 
Appendix B

Opening score of the movement 1 (p1-2)

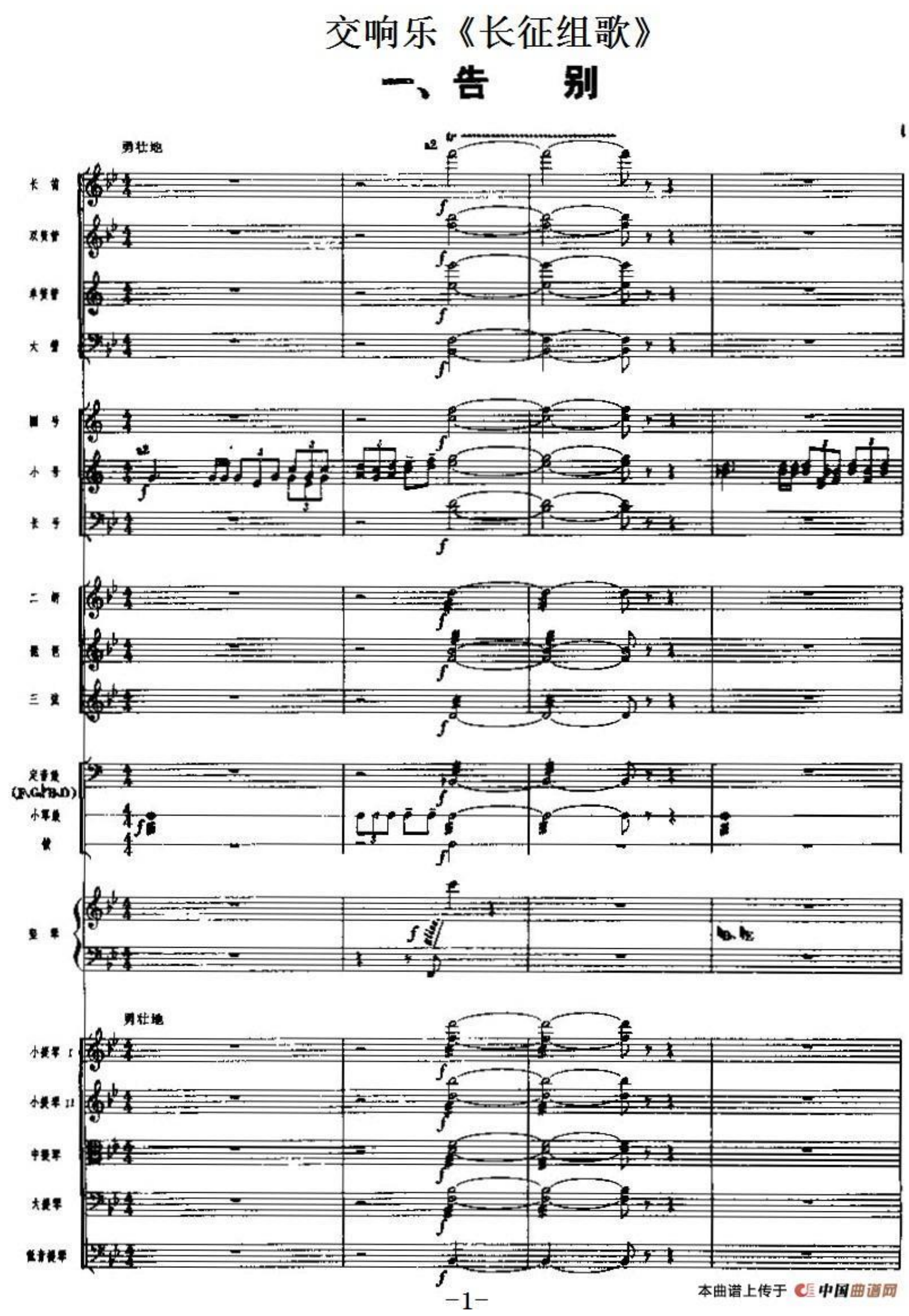




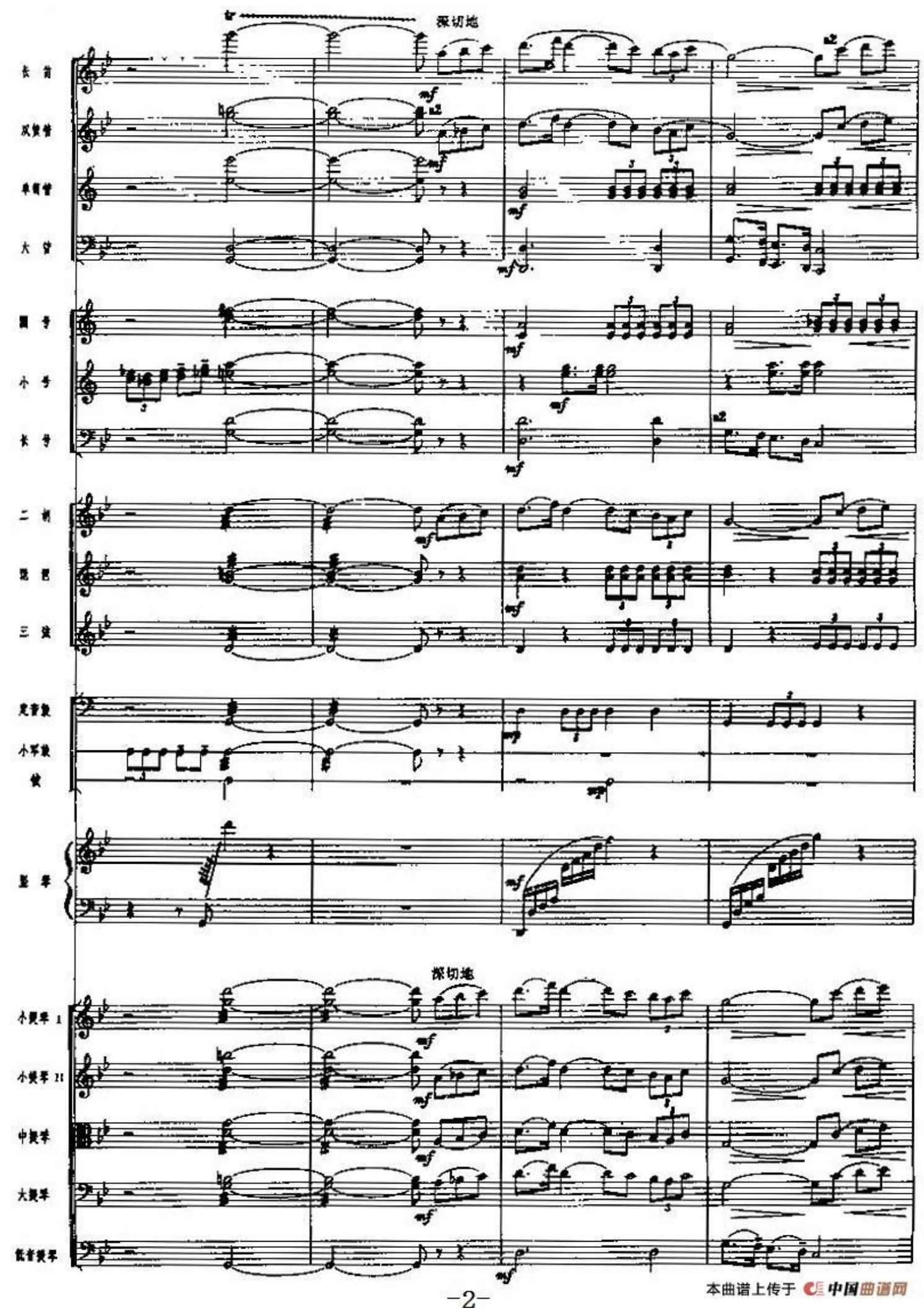


Appendix C

Opening score of the movement 10

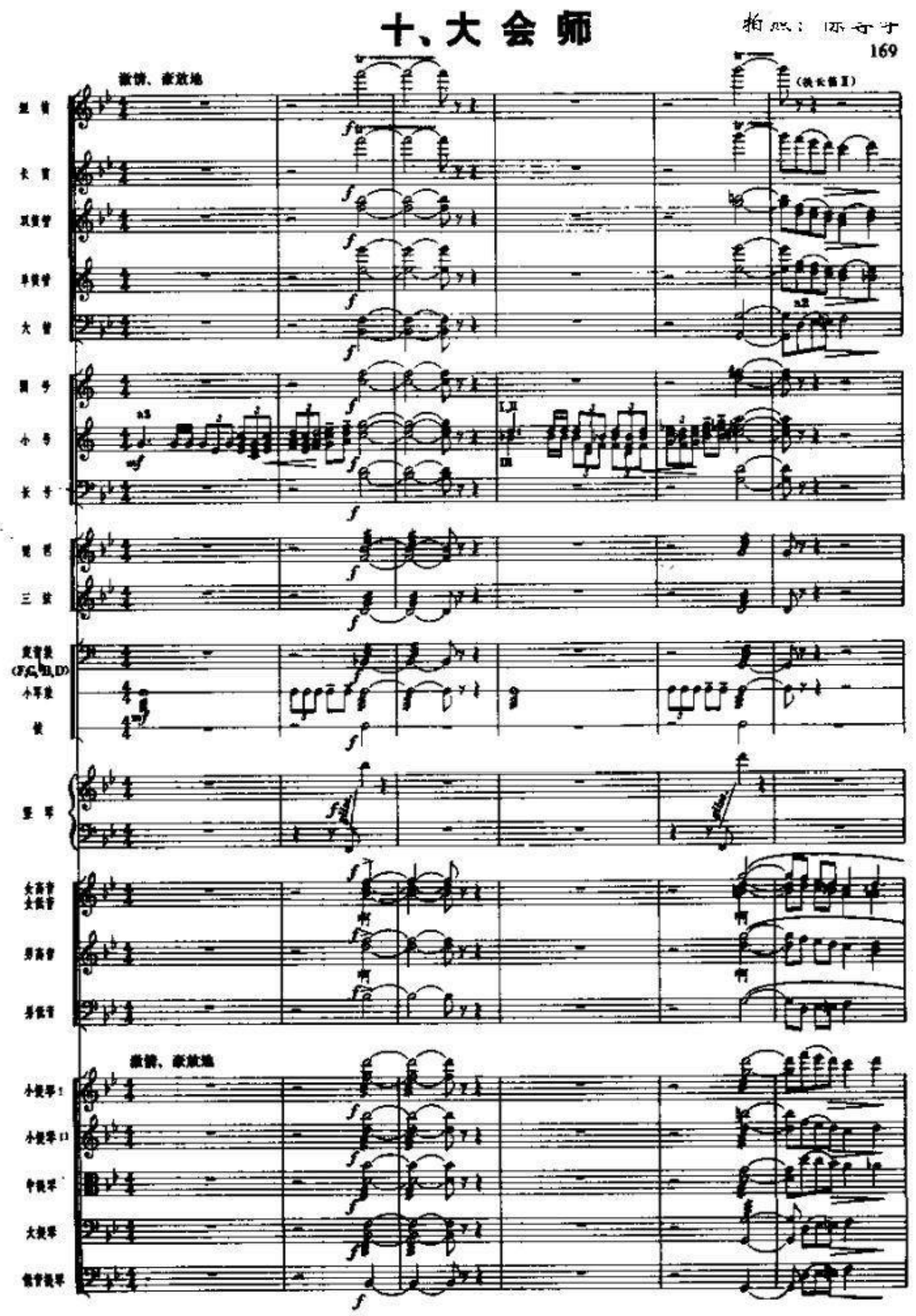


Appendix D

Simplified score of the movement 7. Red box showed folk song style of Shanbei（陕北）。《长征

组歌》: 敲锣打鼓迎红军 秧歌秦腔唱喜悦

http://music.china.com.cn/2016-10/12/content_9085272.htm

\section{长征组歌 (七) 到吴起镇}

(齐唱与二部喝)
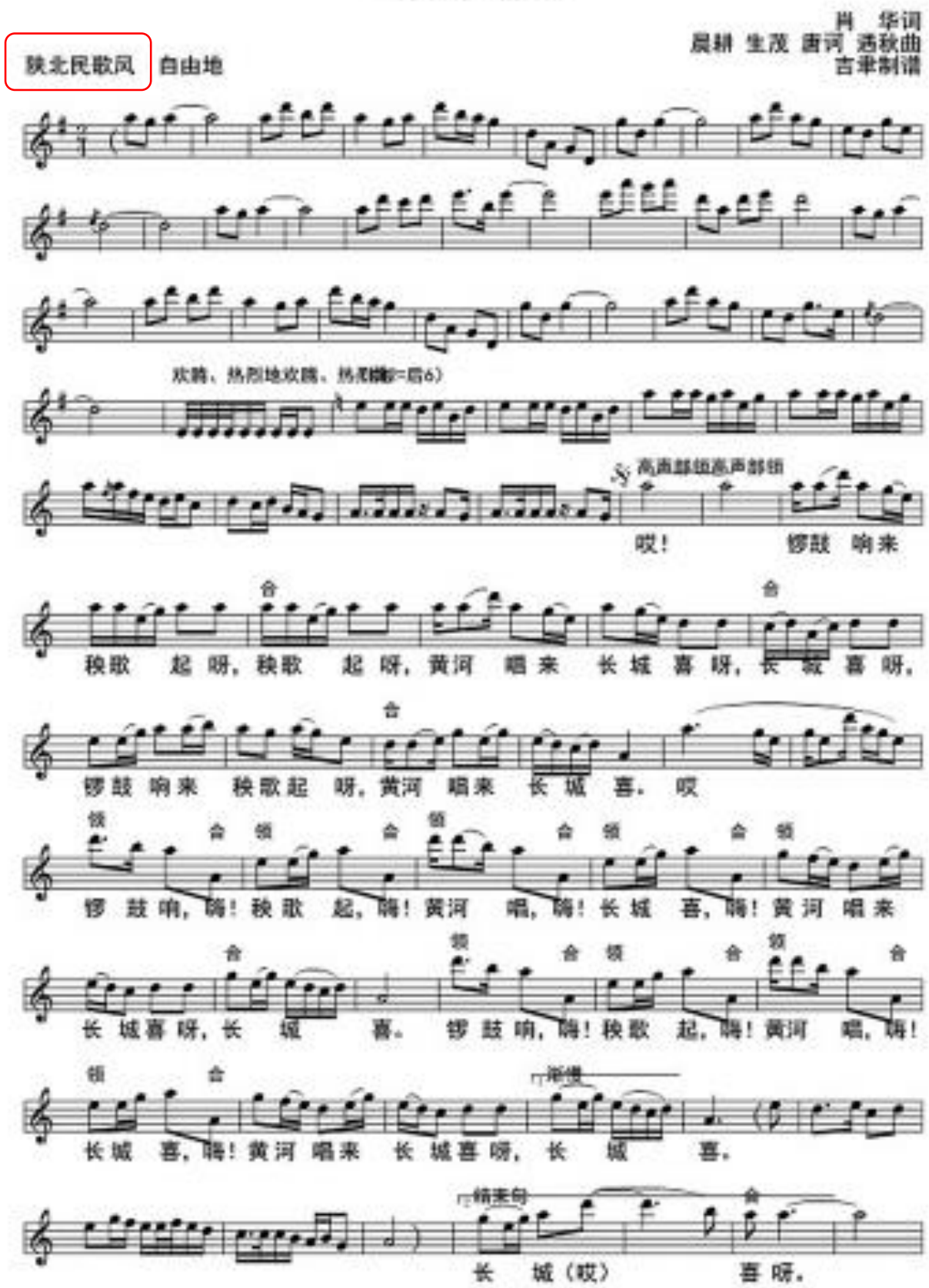